\title{
On The Ease of Being Green: An Investigation of the Inconvenience of Electric Vehicle Charging
}

\author{
James Dixon ${ }^{\mathrm{a}}$, Peter Bach Andersen ${ }^{\mathrm{b}}$, Keith Bell ${ }^{\mathrm{a}}$, Chresten Træholt ${ }^{\mathrm{b}}$ \\ ${ }^{a}$ Dept. of Electronic and Electrical Engineering, University of Strathclyde, Glasgow, UK \\ ${ }^{b}$ DTU Elektro, Denmark Technical University, Lyngby, Denmark
}

\begin{abstract}
This paper presents a quantitative investigation of the inconvenience of electric vehicle $(\mathrm{EV})$ charging relative to internal combustion engine vehicle (ICEV) fuelling in terms of the time penalty likely to be experienced by drivers. A heuristic approach to deriving idealised charging schedules from over 39,000 week-long travel diaries from the UK National Travel Survey is presented in order to quantify the expected convenience parity - the point at which EV charging and ICEV fuelling are of comparable convenience for combinations of battery capacity, charger power and access to charging at different locations (home, workplace and public destinations). It was found that although the majority - up to $95 \%$ - of individuals who can charge at home are expected to be able to reach convenience parity with battery sizes currently available in EV models at the 'affordable' end of the market, this is significantly less likely for those who rely on workplace or public charging and particularly for those who must rely solely on en route charging. These individuals are expected to suffer considerable inconvenience associated with EV charging relative to ICEV fuelling, and although greater battery capacities and charger power ratings are expected to lessen this inconvenience, there remains a significant gap in the convenience of EV ownership between those who can charge while parked at home and those who cannot. Further analysis is carried out to long journeys that cannot be made on a single charge; 'range anxiety' being a major obstacle to widespread EV adoption. It was found that if drivers are compliant with the UK Highway Code in taking regular breaks on long journeys, fewer than $0.01 \%$ of trips are expected to be delayed by charging when using battery capacities of 40-60 kWh.
\end{abstract}

Keywords: Electric Vehicles, Charging, Convenience, E-mobility 


\section{Nomenclature}

\section{Subscripts}

$h \quad$ Denotes the remainder of trips until the next parked charging opportunity or the end of the travel diary

$i \quad$ Denotes each trip in the vehicle's travel diary

$k \quad$ Denotes each potential parked charging event

$o \quad$ Denotes the next charging opportunity or the end of the travel diary

\section{Sets}

I $\quad$ Set of trips in travel diary

$\mathbb{K} \quad$ Set of trips in travel diary that end with a potential parked charging event

$\mathbb{S} \quad$ Set of potential State of Charge increases from possible parked charging events before trip $i$

\section{Variables}

$\bar{v}_{i} \quad$ Average speed $(\mathrm{km} / \mathrm{h})$ of trip $i$

$\Delta^{E V}, \hat{\Delta}^{E V}$ Total charging time penalty (hours) for $\mathrm{EV}$, total charging time penalty normalised by driving time (minutes charging/hours driving) for $\mathrm{EV}$

$\delta_{i}^{e}, \delta_{i}^{f e}, \delta_{i}^{c}$ Charging time penalty (hours) for en route charging events during trip $i$, fixed time penalty (hours) associated with plugging in/removing cable for en route charging events during trip $i$, time penalty (hours) associated with waiting for vehicle to charge for en route charging events during trip $i$

$\delta_{i}^{f u e l}$ Fixed time penalty (hours) associated with fuelling ICEV

$\triangle^{I C E V}, \hat{\Delta}^{I C E V}$ Total fuelling time penalty (hours) for ICEV, total fuelling time penalty normalised by driving time (minutes fuelling/hours driving) for ICEV 
$\delta_{i}^{p}, \delta_{i}^{f p}$ Charging time penalty (hour) for parked charging event following trip $i$, fixed charging time penalty (hours) due to plugging in/removing cable for parked charging event following trip $i$

$\epsilon_{i}, \epsilon^{c} \quad$ Fuel economy of trip $i(\mathrm{~km} / \mathrm{l})$, combined driving cycle fuel economy value $(\mathrm{km} / \mathrm{l})$

$\eta \quad$ One-way efficiency of $\mathrm{AC} / \mathrm{DC}$ converter for parked charging events

$\lambda_{i} \quad$ Decay constant for lithium ion charging curve during constant voltage region for parked charging event following trip $i$

$\Phi_{i}^{C C}, \Phi_{i}^{C V}, \Phi_{i}^{C C-C V}$ Increase in state of charge from constant current parked charging event, increase in state of charge from constant voltage parked charging event, increase in state of charge from parked charging event with both constant current and constant voltage regions

$\Phi_{i}^{p}, \Phi_{i}^{e}$ Increase in state of charge from parked charging event following trip $i$, increase in state of charge from en route charging events during trip $i$

$\Pi_{i} \quad$ Decision variable $\{0,1\}$ to denote whether parked charging action taken following trip $i$; 0 if no parked charging action taken, 1 if parked charging action taken

$\varepsilon_{i} \quad$ Remaining energy required for trips up to the next parked charging opportunity (or the end of the travel diary), including that of the current trip $i(\mathrm{kWh})$

C Battery capacity $(\mathrm{kWh})$

$c_{i}, c^{c} \quad$ Energy consumption $(\mathrm{kWh} / \mathrm{km})$ of trip $i$, combined driving cycle energy consumption value $(\mathrm{kWh} / \mathrm{km})$

$d_{i} \quad$ Distance $(\mathrm{km})$ of trip $i$

$E_{i} \quad$ Energy demand for trip $i(\mathrm{kWh})$

F Vector containing possible increases in state of charge following potential parked charging events

$f_{i}, f^{\text {min }}$ Fuel requirement of trip $i(\mathrm{l})$, minimum permissible fuel (l) 
$h \quad$ Hours of driving before 15 minute break is mandated

$n_{i} \quad$ Number of en route charging stops necessary on trip $i$

$P_{i}^{D C}, P_{i}^{A C}$ Maximum rated DC charging power $(\mathrm{kW})$ available during parked charging event following trip $i$, Maximum rated AC charging power $(\mathrm{kW})$ available during parked charging event following trip $i$

$P^{e} \quad$ DC charging power $(\mathrm{kW})$ available during en route charging events

$Q \quad$ local variable in parked charging scheduling algorithm used to track improvements to the state of charge by taking parked charging events

$r^{\text {min }}$ Minimum permissible remaining range of vehicle $(\mathrm{km})$

$S_{i}, S^{\text {min }}$ State of charge after trip $i$ including the addition due to any associated charging during or after the trip, minimum permissible state of charge

$t_{i}^{0.8}, t_{i}^{\infty}$ Time (hours) at which vehicle reaches state of charge of 0.8 in parked charging event following trip $i$, time (hours) at which the charging power reaches a value close to zero (taken as $1 \%$ of the maximum rated power) in parked charging event following trip $i$

$t_{i}^{s}, t_{i}^{d} \quad$ Time (hours) at which vehicle starts parked charging event following trip $i$, time (hours) at which vehicle departs parked charging event following trip $i$

$T_{i} \quad$ Duration (hours) of trip $i$

$V \quad$ Volume of ICEV fuel tank (1)

$Z_{i} \quad$ State of charge after trip $i$ not including the addition due to any associated charging during or after the trip

\section{Introduction}

\subsection{Barriers to Electric Vehicle Adoption: Realities and Perception}

The electrification of the private vehicle fleet is cited as a key contributor to a reduction in carbon dioxide emissions and air pollution by governments worldwide - for example, the UK's Committee on Climate Change 
has stated that all new cars and vans sold in the UK should be electric by 2035 at the latest, with cost savings projected as a result of an earlier switch [1]. However, a major obstacle to widespread battery electric vehicle (EV) adoption is the perception that their charging carries a significant amount of inconvenience relative to the fuelling of internal combustion engine vehicles (ICEVs). This perception is grounded in two facts:

1. Battery storage is far less energy dense than the storage of hydrocarbon fuels in a tank. The US Department of Energy assumes the energy content of a US gallon (3.89 litres) of petrol to be $33.7 \mathrm{kWh} \mathrm{[2].} \mathrm{On} \mathrm{this}$ basis, even a small 'city' ICEV model such as a 2018 Fiat 500 with a 40 litre petrol tank [3] effectively has an energy storage capacity of over 340 $\mathrm{kWh}$, compared to $40 \mathrm{kWh}$ available in the 2018 Nissan Leaf, an EV at the lower end of the market in terms of price [4]. Due to the significantly greater losses associated with the combustion engine of an ICEV than those associated with the motor and traction drive of an EV [5], EVs can travel around 3-4 times further on the same amount of energy storage. However, differences in vehicles' energy storage capacities still imply a large gap — at least for now - between the ranges of EVs and similarly priced ICEVs.

2. Battery charging must be done at a far slower rate than fuelling a car. Whereas even the highest projected power ratings of future EV charging mentioned in academic and industrial literature are limited to hundreds of $\mathrm{kW}$ [6-10], the effective 'charge rate' of a light passenger ICEV is around $5000 \mathrm{~kW}$ taking into account combustion engine losses [11]. This implies that — at least for now — charging EVs will take more time than fuelling ICEVs.

In contrast, whereas the fuelling of an ICEV must be done by the user as they stand at a petrol pump, having visited a petrol station specifically to replenish the energy storage content of their vehicle - an activity that was found to take around 3-5 minutes (section 2.9) - an EV can be charged while it is parked at home, work or in another private or public location with a significantly smaller time penalty associated with plugging in and removing the charging cable. The only occasions when users will have to wait for their EV to be charged are when, on a long journey or on multiple trips lacking an opportunity to charge at destinations, the battery's State of Charge (SoC) has reached such a level that the user must make a specific 
charging stop. If the total duration of these occasions was less than the total duration of fuelling stops at petrol stations required by ICEVs, it could reasonably be argued that charging an EV is of greater convenience than fuelling an ICEV. The frequency and duration of charging occasions would depend on the battery capacity of the EV, the rate at which it could charge its battery and its access to a variety of charging locations (e.g. at home, work and public destinations).

Several studies have examined the physical limitations of electric transport. Axsen et al [12] establish that battery technology limitations and high battery cost are the major obstacles to widespread adoption of EVs. The study reflects on the fast pace of development of EV battery sizes and charging capacities in the goal of attaining a level at which they will, suddenly, become acceptable to most users. The question on how much range an EV needs is multi-faceted in both technological and social contexts. Pearre et al [11] conduct a study on a year's worth of real vehicle monitoring data to establish the required range to complete a day's driving (it is assumed that vehicles can charge every night and start the next day with a full battery). It was found that $21 \%$ of drivers in the sample could substitute their ICEV for a modern EV in the 'affordable' sector of the market such as the 40 kWh capacity, 150-mile range 2018 Nissan Leaf [3] without a single day of adjustment to their normal travel schedules, while $60 \%$ of drivers from the same sample could substitute for the same EV if they were willing to make adjustments to six days in the year.

Although the results presented in the literature suggest that in most cases there is only a slight adjustment of lifestyle required for the adoption of an $\mathrm{EV}$, consumers remain resistant to EVs [13]. While this may partially be due to a tendency to resist the adoption of any new technology due to lack of knowledge, high initial costs and low risk tolerance [14], the main reason for a consumer not wanting to substitute their ICEV for an EV is usually cited as so-called 'range anxiety' [15-18], so much so that the willingness to pay to extend driving range is reported as being between $€ 30-100$ per additional km [16, 17]. In [18], Franke et al compile responses from surveys of the acceptable range an EV would have to have before a consumer would consider the substitution of their ICEV for one; all six of the comparable studies cite a range of at least $300 \mathrm{~km}$.

The subject of long journeys and the perceived inconvenience of having to stop to charge multiple times is clearly an important one to would-be EV consumers. However, it is suggested that natural breaks taken as part of 
long journeys regardless of the vehicle's propulsion system are overlooked; if the driver could fit necessary charging sessions into natural breaks then the inconvenience of using an EV for that journey would be reduced.

\subsection{Contribution}

The key contribution of this paper is the quantification the inconvenience - defined as the total time penalty - of EV charging based on the analysis of 39,020 week-long travel diaries synthesised from the UK National Travel Survey (NTS). The charging time penalty is assessed in respect of two types of charging event: one where the vehicle is parked at home, work or a public destination; the other en route. In both cases, a time penalty is applied associated with the time taken to plug in and remove the charging cable. However, in the former type of charging event it is assumed that while the car is parked, the user is engaged in an activity that is unaffected by how they came to be at that location and therefore is not inconvenienced by the use of an EV. In the latter, it is assumed that the user is inconvenienced by being forced to wait for the car to be charged and so the charging time is added as a further time penalty. The charging time penalties are evaluated by a heuristic algorithm presented in this paper that derives an idealised charging schedule for each travel diary such that the vehicle's SoC is kept above a prescribed level throughout subject to the minimum number of charging events, scheduling parked charging events before resorting to en route charge events because of their smaller time penalty.

This analysis is carried out for different EV battery capacities, charger power ratings and levels of access to charging locations (i.e. home, work and public destination) and the results are compared to the expected time penalty associated with ICEV fuelling for the same travel diaries, based on a fixed time penalty associated with each fuelling stop. This allows the quantification of combinations of battery capacity, charger power rating and level of access to charging at different locations necessary for would-be EV drivers to be able to switch their ICEV for an EV without suffering an amount of inconvenience, given the same travel habits.

Particular attention is paid to long journeys - those whose distance is greater than can be made on a single charge - to investigate the likely inconvenience added to these journeys as a result of charging, given that at least some charging can be fitted into natural breaks that are taken on long journeys. Analysis is carried out for two cases: one where it is assumed that drivers follow UK Highway Code Rule 91 [19] which mandates 15 minutes' 
rest for every 2 hours of driving, and a sensitivity case where it is assumed drivers take a 15 minute break only once every 4 hours.

\subsection{Simplifying Assumptions}

\subsubsection{Idealised Charging Schedules}

The modelling presented in this paper minimises the level of inconvenience that both EV and ICEV users would experience by representing idealised charging and fuelling behaviour. While this assumption will affect the time penalty suffered by EV users more than that suffered by ICEV users due to their shorter range and therefore greater number of charging/fuelling stops, EV users' ability to learn the charging requirements associated with their vehicles and minimise the number of times it needs to be plugged in has been observed $[20,21]$. Although a driver's actual charging pattern may differ from that derived in the model, drivers are likely to exploit opportunities to charge when the vehicle would be parked anyway and their desire to minimise dependency on en route charging are likely to give comparable results in respect of inconvenience. To assist the driver in minimising their charging inconvenience, smartphone apps such as Zap-Map's Journey Planner [22] are available that, given access to a driver's planned journeys and public data on charger locations, will advise the driver on the optimal charging schedule.

The potential value of a sensitivity study to the effect of human behaviour and 'non-ideal' decision making in the scheduling of EV charging and the resulting inconvenience is suggested as a piece of further work in section 5 .

\subsubsection{Availability of Charging and Fuelling Infrastructure}

In the absence of any data allowing a comparison to be made on the time taken to find an EV charger or petrol station, this study does not consider any inconvenience associated with finding an EV charger or petrol station, and it is assumed that i) an EV charger is available at any home, work or public destination providing the $\mathrm{EV}$ in question has that level of charging access, and ii) an EV charger or petrol station is immediately available at the point an EV or ICEV reaches a minimum range of $25 \mathrm{~km}$ remaining, taken to represent the smallest amount of charge that a prudent driver would be willing to have in the battery or fuel tank.

While this is anticipated to have a significant impact on the results presented, the assumption can be justified by considering the following. If a driver has access to charging at their home or workplace, then they are expected to be able to use that charger whenever they need to, as these 
destinations are likely to be the same physical locations every time. The main exceptions to this would be if another vehicle at their home is using the household charger or if provision of charging at their workplace is insufficient to service the number of EVs that require charging. Public charging is different, as these destinations are likely to correspond to a much larger set of physical locations. Here, the successful access rate of charging would depend on whether the public destination in question has EV charging infrastructure installed. The assumption is made that EV charging infrastructure can be found at any of a set of public locations detailed in section 2.2.3; in doing so, the results of this paper reflect a scenario where EV charging infrastructure is plentiful. According to [23], there are currently (as of September 2019) 25,959 public EV charging connections across 9,580 locations in the UK and the number of connections has increased by over $45 \%$ in the last 12 months. Compared to the total number of UK petrol stations of 8,422 , which is in a continuing trend of decline [24], EV charging infrastructure is clearly gaining itself a greater presence. Furthermore, [25] and [26] both suggest that EV drivers are likely to actively seek out destinations (such as supermarkets, hotels and restaurants) that offer charging opportunities, and journey planning smartphone applications such as [22] will assist drivers in finding them. This suggests a commercial incentive on such destination charging being made available in order to attract custom from EV owners reliant on public charging, as is already being seen: for example, as of August 2019, three of the UK's biggest supermarket chains have announced plans to install free-to-use EV charging infrastructure at their stores by 2020 [27-29].

As this assumption is likely to significantly affect the results presented, the consideration of non-binary levels of access to charging at locations is highlighted as a valuable piece of further work in section 5 .

\subsubsection{Boundary Conditions}

To offer a fair as possible comparison between the time penalties associated with charging an EV and fuelling an ICEV over the course of a week-long travel diary, the charging schedules were derived on the basis such that the energy content of the vehicle at the end of the travel diary must be equal to that at the start. It is assumed that an EV's initial SoC (and therefore the SoC it must end its travel diary with) is $80 \%$, given that the time taken to charge between $80-100 \%$ is disproportionately longer than the time taken to charge between $0-80 \%$ (this is further explained in section 2.5.2). By comparison, an ICEV's fuelling time penalty is calculated as a proportion of a 
fixed (minimum fuel level to full tank) fuelling time penalty, according to the volume of fuel it consumes over the course of the travel diary. Effectively, it is assumed that an ICEV will wait until it reaches the minimum fuel level before carrying out a full refuel — the most time-efficient fuelling action possible.

\subsubsection{Charging During Long Journeys}

In this paper it is assumed that drivers would try to fit EV charging on a long journey into natural breaks - taken regardless of the vehicle's form of propulsion - wherever possible, given that such breaks are often taken where charging infrastructure is increasingly present, e.g. motorway service stations [30]. Therefore, the en route charging time penalty is adjusted to account for any breaks taken. To allow fair comparison, the same analysis is carried out for ICEV fuelling on long journeys.

Although there is data in the NTS for breaks taken during journeys (given by the difference between the fields 'total time' and 'trip time'), it is suggested that these are likely to be under-reported: $82 \%$ of journeys over $200 \mathrm{~km}$ and $77 \%$ of journeys over 4 hours are without any recorded breaks. Due to the likely unreliable nature of this data, this paper assumes a constant rate of breaks per driving time for one of two cases: in the first case it is assumed that all drivers are compliant to UK Highway Code Rule 91 [19], in which 15 minutes' break is advised for every 2 hours of driving. As it is recognised that this has a considerable effect on the resulting inconvenience of charging and drivers may not be compliant to the Highway Code, a sensitivity case of 'half' Rule 91 - a 15 minute break for every 4 hours of driving — is also presented.

\subsubsection{Fixed Arrival Times and Infeasible Travel Diaries}

While time penalties are attributed to both parked and en route charging events, arrival times of journeys are not adjusted to account for stops due to charging because there is not sufficient information on how an individual's arrival time would affect a subsequent departure time: on some occasions, such as a visit to a leisure destination, a late arrival would result in a late departure as the time at the destination could be considered fixed. However, on other occasions, such as arriving home from work before leaving the next morning, a late arrival due to a charging stop on the journey home would likely not lead to a late departure time, which could be considered fixed. As a result, travel diaries are not adjusted to account for charging stops. However, 
the number of travel diaries that are rendered infeasible by the presence of charging (by at least one journey being delayed past the subsequent departure of the next trip) is reported for all variations of battery size, charger power and access to charging at different locations (section 3.3).

\subsubsection{Zero Battery Degradation}

Lithium ion batteries degrade with use, a process whose rate depends on a wide variety of factors including temperature, rates of charge and discharge, depth of discharge, SoC and total energy withdrawn [31]. It has been documented in [32] that aged batteries can experience a capacity fade of at least $20 \%$, which would linearly affect the range of the vehicle. While this is acknowledged to affect the resulting inconvenience of charging as vehicles will have to seek more charging opportunities as their battery capacities fade, the first purpose of this paper is to assess convenience and whether it is rational for inconvenience to influence choice of vehicle when it is being bought new. It is assumed that the entirety of the batteries' capacity can be used, at least initially, save for the minimum range that the vehicle must retain. However, some linear extrapolation can be applied to the results presented: for example, a $20 \%$ capacity fade on a $30 \mathrm{kWh}$ battery will result in the $\mathrm{EV}$ having an achievable range equal to that of one with a $24 \mathrm{kWh}$ battery, ignoring any differences in the vehicle's energy consumption and any effect on the charging rate attainable following the capacity fade. There are other effects that result from the degradation of batteries, which are discussed as points of further work in section 5 .

\section{Method}

\subsection{Travel Data from the UK National Travel Survey}

Insight into individuals' travel habits can be provided by the analysis of travel survey data; that is, self-reported data of trips made by individuals over a period of time. The NTS is one such survey, conducted annually for around 15,000 residents in which they record all trips taken over a 7-day period [33]. The 7-day period recorded differs between the individuals recording the data, hence minimising any bias from seasonal effects and holidays. Data for the years 2012-2016 as used in this study contains details of 598,645 car-based trips made over the period.

To justify use of 5 years' worth of NTS data, Figure 1 shows the variation in trip distance $(\mathrm{km})$ and time (minutes) of all car-based trips between 
years. The mean distance varies only within the range $14.42-14.80 \mathrm{~km}$ and the mean time varies within the range 21.38-22.81 minutes (both 2012-2015 respectively). Although the variation within each year is significant as shown in Figure 2, the variation between years is evidenced to be very slight.
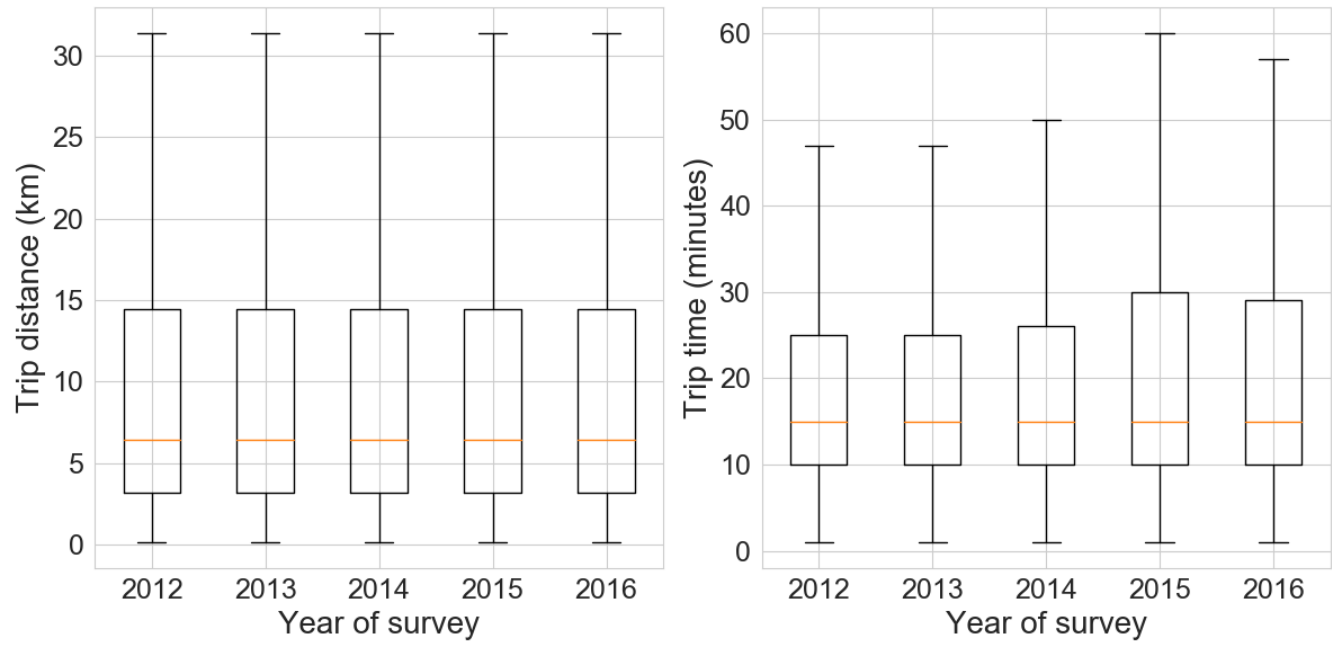

Figure 1: Boxplots showing variation in trip distance $(\mathrm{km})$ and duration (minutes) across 5 years of UK National Travel Survey (NTS) data (outliers omitted for clarity)

The NTS contains two tables of relevance to this study: a trip dataset and a vehicle dataset. The trip dataset contains data pertaining to the distance, duration, time/day of departure, mode of transport and purpose of each trip recorded. Associated with each trip is an ID of the individual who took the trip, but trips are not associated directly with a vehicle. In order to synthesise week-long travel diaries for each vehicle, the vehicle and trip datasets were matched up. The vehicle dataset contains information on each of the vehicles within the NTS, including the ID of the 'lead driver' with whom the vehicle is associated. Note that in the NTS, multiple vehicles can be associated with one individual but a single vehicle cannot be linked with more than one individual. For each individual, a list of vehicles associated with that individual is returned. If the individual is assigned to more than one vehicle (6.6\% of the total individuals were assigned to more than one vehicle), then the 'vehicle availability' - which describes how often the vehicle is used - for each vehicle is returned. If only one of the vehicles assigned to this user is described as being in regular use, all trips associated with this individual ID 
are assigned to the vehicle in regular use. If more than one vehicle is described as being in regular use, then trips are assigned at random to the vehicles that are said to be in regular use by that individual. $5.4 \%$ of individuals claimed to have more than one vehicle in regular use. The result of the processing of the NTS dataset is a set of week-long travel diaries for 39,020 vehicles.

Figure 2 shows the spread in data of all 39,020 car-based travel diaries used in this study in terms of the distance driven, the number of trips taken and the total driving time.
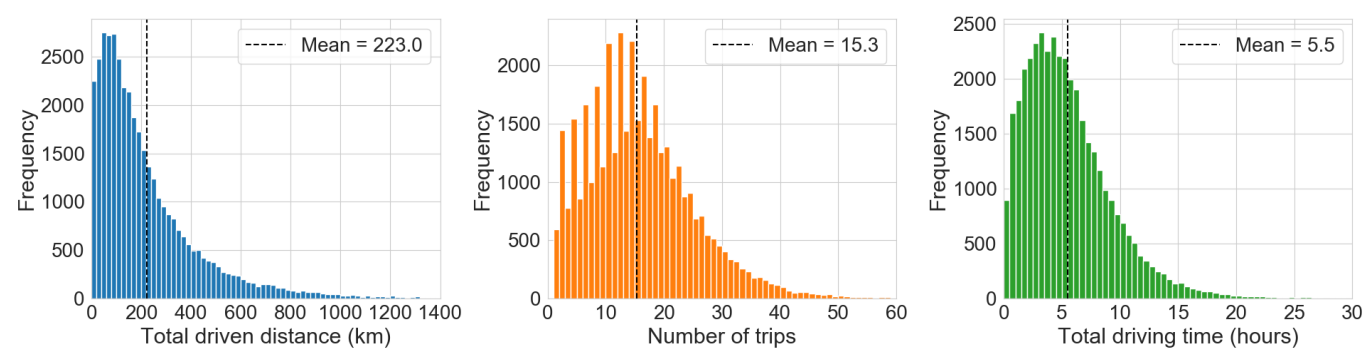

Figure 2: Histograms showing spread of distance driven, number of trips taken and total driving time across 39,020 travel diaries synthesised from the UK National Travel Survey dataset

Figure 2 shows that there is a significant spread in individuals' driving habits. It is shown that the number of trips is more likely to be even than odd. This is suggested to be due to there being more return trips in weeklong travel diaries than one-way trips. The mean corresponds to an average of 1.1 return trips per day. Individuals spent a mean time of 5.5 hours driving in the week covering a mean distance of $223 \mathrm{~km}$. However, the modal times and distances are significantly less than this (approximately 3 hours and 80 $\mathrm{km}$ respectively), showing that the small number of individuals who drove considerably more than the majority increase the mean driving behaviour. Due to the large variance in the data, results from the assessment of EV charging inconvenience will be expressed as the total time penalty due to charging (in minutes) per total time spent driving (in hours, as per the data in Figure 2), to allow the results to be more easily compared across the spectrum of driving behaviours. 


\subsection{Parameters}

\subsubsection{Battery Capacity and Energy Consumption}

Battery capacities found on variants of two of the highest-selling EVs on the global market are used for reference: the lower-range Nissan Leaf and the longer-range, higher-priced Tesla Model S. The energy consumption values used are taken from the US Environmental Protection Agency (EPA)'s fuel economy test data [3], whose Federal Test Procedure is designed to allow direct comparison of emissions and fuel economy between different vehicles for real-world driving conditions based on city and highway driving cycles. Values used are shown in Figure 3 along with battery capacity for the vehicle models discussed.

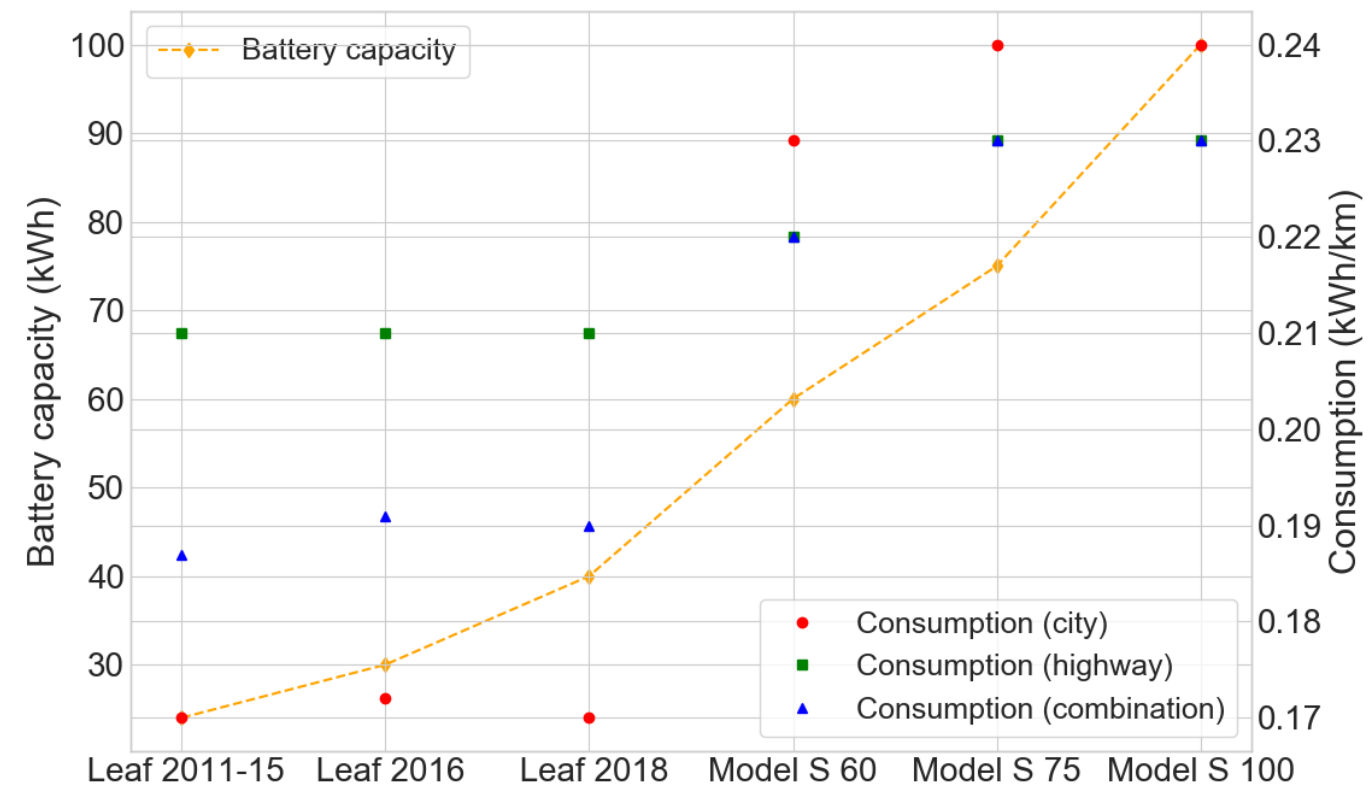

Figure 3: Energy consumption values (city, highway and combined) for vehicles considered in study (data from [3])

\subsubsection{Charger Ratings}

The effect of charger rating is investigated by using 'low power' and 'high power' scenarios (Table 1).

The low power scenario is based on 'slow' home charging (single phase 16 A, $230 \mathrm{~V}$ ) and workplace/public destination charging (three phase 16 A, 230 
Table 1: Charging scenarios used in synthesis of charging diaries

\begin{tabular}{llll}
\hline $\begin{array}{l}\text { Charging } \\
\text { scenario }\end{array}$ & $\begin{array}{l}\text { Home } \\
\text { Charging } \\
(\mathbf{A C})\end{array}$ & $\begin{array}{l}\text { Workplace/ } \\
\text { Destination } \\
\text { Charging } \\
\text { (AC) }\end{array}$ & $\begin{array}{l}\text { En Route Charging } \\
(\mathbf{D C})\end{array}$ \\
\hline Low Power & $3.7 \mathrm{~kW}$ & $11 \mathrm{~kW}$ & $\begin{array}{l}50 \mathrm{~kW} \text { for battery capac- } \\
\text { ity }<60 \mathrm{kWh} 120 \mathrm{~kW} \\
\text { for battery capacity } \geq 60 \\
\text { High Power }\end{array}$ \\
& $7.4 \mathrm{~kW}$ & $22 \mathrm{~kW}$ & $\begin{array}{l}150 \mathrm{~kW} \text { for battery capac- } \\
\text { ity }<60 \mathrm{kWh} 350 \mathrm{~kW} \\
\end{array}$ \\
& & $\begin{array}{l}\text { for battery capacity } \geq 60 \\
\mathrm{kWh}\end{array}$ \\
\hline
\end{tabular}

$\mathrm{V}$ ); en route charging rate are based on those currently widely available [30]. The high power scenario is based on 'fast' home charging (single phase 32 A, $230 \mathrm{~V}$ ) and workplace/public destination charging (three phase $32 \mathrm{~A}, 230$ $\mathrm{V})$; en route charging rates are based on projected near-future developments further discussed in section 4 .

\subsubsection{Charging Access}

The NTS trip data contains a field on the destination of the journey. For home and work charging, the destination is clear-cut as 'home' for home charging and 'work' or 'education' for work charging. For public destination charging, judgement was taken to ascertain which destinations could likely see charging opportunities. Table 2 shows an exhaustive list of destinations from the NTS data (except 'home', 'education' and 'work') and a True or False value to indicate whether vehicles are assumed to be able to charge at that destination. The philosophy of this was to allow charging at locations where chargers are currently found [23] and not at the end of escort journeys (i.e. when the purpose of the journey was to drive another individual to a destination), visiting friends or on holiday. 
Table 2: Public destination charging availability in study

\begin{tabular}{ll}
\hline Public destination charging $=$ & Public destination charging $=$ \\
TRUE & FALSE \\
\hline Food shopping & Escort work \\
Non food shopping & Other escort \\
Eat/drink with friends & Escort home \\
Day trip/just walk & Visit friends \\
Sport: participate & Holiday: base \\
Personal business eat/drink & Escort shopping/personal business \\
Other social & In course of work \\
Entertain/ public activity & Escort education \\
Personal business other & Escort in course of work \\
Personal business medical & Other non-escort \\
\hline
\end{tabular}

\subsection{Charging Time Penalties}

Although one argument made in favour of the convenience of EV use is that they can be charged while the user is otherwise engaged, there is a time penalty associated with plugging in and removing the charging cable. Time penalties for such as used in this study are derived from experiments carried out at DTU PowerLab with a Renault Zoe EV for both fixed cable (in which the cable is already in situ with one end already plugged into the charger, typical of home and en route applications) and loose cable (in which the cable must be taken from the car before plugging in to both the car and the charger itself, typical of work and destination applications). For the fixed cable scenario, the plug-in time is the time taken to walk from the driver's side door to the charger at the front of the car, take the cable from the charger and insert it into the car's charging socket - also on the front of the car. The removal time is the time taken to unplug the cable from the car, return it to the charger and walk to the driver's side door. For the loose cable scenario, the plug-in time is the time taken to walk from the drivers' side door to the car's boot, remove the cable, close the boot, walk with the cable to the charger at the front of the car and use the cable to connect the car with the charger. The removal time is the time taken to unplug both ends of the cable, walk to the car's boot and open it, put away the cable, close the boot and walk back to the driver's side door. Three trials of plugging in and removing the cable for both fixed and loose cable set ups by an individual familiar with the process of EV charging were performed; the results are 
shown in Table 3.

Table 3: Experimental results: plugging in and removal time for charging cable

\begin{tabular}{llllllllll}
\hline Cable & \multicolumn{4}{c}{ Plug-in time $(\mathrm{s})$} & \multicolumn{4}{c}{ Removal time $(\mathrm{s})$} & Total time \\
Scenario & 1 & 2 & 3 & Mean & 1 & 2 & 3 & Mean & penalty (s) \\
\hline Fixed Cable & 8.3 & 9.4 & 8.9 & $\mathbf{8 . 9}$ & 7.3 & 8.5 & 8.6 & $\mathbf{8 . 1}$ & $\mathbf{1 7 . 0}$ \\
Loose Cable & 27.7 & 27.2 & 28.2 & $\mathbf{2 7 . 7}$ & 21.7 & 21.2 & 20.8 & $\mathbf{2 1 . 2}$ & $\mathbf{4 8 . 9}$ \\
\hline
\end{tabular}

The total time penalty in Table 3 is applied to every charging event returned. The time taken to charging for each charging type is given as follows:

- For charging while parked at home: a fixed cable time penalty (17.0 s) is applied to each charging event

- For charging while parked at work or a public destination: a loose cable time penalty $(48.9 \mathrm{~s})$ is applied to each charging event

- For en route charging: a fixed cable time penalty (17.0 s) is applied to each charging event in addition to the time taken to carry out the necessary charging

Note that although these time penalties are given in seconds, they are converted to hours for all equations presented in this paper.

The time elapsed between stopping and exiting the car, and between reentering the car and starting to move again, is neglected in the calculation of both parked and en route charging events. For parked charging events, this is based on the assumption that the driver would be leaving the vehicle regardless of whether a charging action would be taken, because all parked charging events are taken at destinations (home, work or public) that the driver will come to be at regardless of the type of vehicle they arrive in. Therefore, the time penalty of this event is the detour from their intended trajectory, as quantified by the time penalties in Table 3. For en route charging events, although the time taken to exit and re-enter the car would represent an additional time penalty, it is negligible in comparison to the time spent charging the vehicle. 


\subsection{Heuristic to Evaluate Idealised Charging Schedule Given a Travel Diary} from the UK National Travel Survey

\subsubsection{Overview}

The total time penalty of EV charging is calculated by a heuristic method that derives an idealised charging schedule to cover the energy requirements of any given seven-day travel diary from the UK NTS. It will return the minimum number of charging events in order to maintain the vehicle's SoC at a sufficient level, choosing parked charging events first and then resorting to en route charging events only when it cannot meet the travel diary's energy requirement by parked charging alone.

The heuristic is based on the assumption that parked charging will always carry a lesser time penalty than en route charging, and will return the optimum charging schedule given this assumption. The following sections describe the process followed by the heuristic presented in this paper.

\subsubsection{Energy Requirement for Travel Diary}

II denotes the set of trips in a vehicle's travel diary. For each trip $i, i \in \mathbb{I}$, the average speed $\bar{v}_{i}(\mathrm{~km} / \mathrm{h})$ is calculated from the trip distance $d_{i}(\mathrm{~km})$ and total trip duration $T_{i}$ (hours) (1).

$$
\bar{v}_{i}=\frac{d_{i}}{T_{i}}
$$

The vehicle's energy consumption (Figure 3) is defined for three types of trip: 'city', 'highway' and 'combined'. The assignment of a particular journey to one of these types is based on average speed: 'city' for journeys with an average of less than $50 \mathrm{~km} / \mathrm{h}$, 'highway' for journeys with speeds greater than $100 \mathrm{~km} / \mathrm{h}$ and 'combined' for journeys with speeds in between. These speed thresholds are based on free-flow traffic speed recorded on roads in Britain [34].

Following the setting of the vehicle's energy consumption $c_{i}(\mathrm{kWh} / \mathrm{km})$ during trip $i$, the energy demand $E_{i}(\mathrm{kWh})$ of trip $i$ is calculated (2).

$$
E_{i}=d_{i} c_{i}
$$

The SoC (per unit) $S_{i}$ at the end of each trip, including any en route charging during the trip and any parked charging immediately after the trip, is set as in the energy balance in (3). 


$$
S_{i}=S_{i-1}-\frac{E_{i}}{C}+\Pi_{i} \Phi_{i}^{p}\left(t_{i}^{s}, t_{i}^{d}, P_{i}^{D C}\right)+\Phi_{i}^{e}\left(S_{i-1}, \varepsilon_{i}\right)
$$

where:

- $C$ is the vehicle's battery capacity $(\mathrm{kWh})$.

- $\Pi_{i}$ is a decision variable $\{0,1\}$ for parked charging at the end of trip $i$; 0 if no parked charging action taken, 1 if parked charging action taken.

- $\Phi_{i}^{p}$ is the increase in SoC from a parked charging event at the end of trip $i$; a function of $t_{i}^{s}$, the time (hours) at which the vehicle starts the parked charging event after trip $i, t_{i}^{d}$, the time (hours) at which the vehicle stops the parked charging event after trip $i$ (and hence starts its next trip) and $P_{i}^{D C}$, the maximum rated DC charger power $(\mathrm{kW})$ available during the parked charging event following trip $i$.

- $\Phi_{i}^{e}$ is the increase in SoC from en route charging events within trip $i$; a function of the SoC after the previous trip and any charging events during or immediately afterwards $S_{i-1}$ and $\varepsilon_{i}$, the remaining energy requirement until the next charging opportunity (or, if there are no charging opportunities following trip $i$, the end of the travel diary).

In order to schedule charging events, two further variables must be established. Firstly, $S^{\text {min }}$ is the minimum allowable SoC (4) based on a prescribed minimum range $r^{\text {min }}$ of $25 \mathrm{~km}$ driven at the combined energy consumption value $c^{c}$ from Figure 3. Secondly, $Z_{i}$ is the SoC after each trip $i$ before the addition of any charging associated with that trip (5).

$$
\begin{gathered}
S^{m i n}=\frac{r^{m i n} c^{c}}{C} \\
Z_{i}=S_{i-1}-\frac{E_{i}}{C}
\end{gathered}
$$

The heuristic (Figure 4) starts by initialising all parked charging decision variables $\Pi_{i}$ and all increases in SoC from parked charging and en route charging $\Phi_{i}^{p}$ and $\Phi_{i}^{e}$ respectively equal to zero for all trips. The SoC at the start of the travel diary $S_{0}$ is set to 0.8 for reasons described in section 1.3.3. The SoC $S_{i}$ after each trip $i$ - currently with no addition from charging - is calculated for all trips from (3). If $S_{i}$ for all trips is greater than or 
equal to the minimum SoC $S^{\text {min }}$, then no charging is required. If not, parked charging events are scheduled according to the method described in section 2.5. If at this point any $S_{i}$ remains less than $S^{\text {min }}$, en route charging events are scheduled as described in section 2.6.

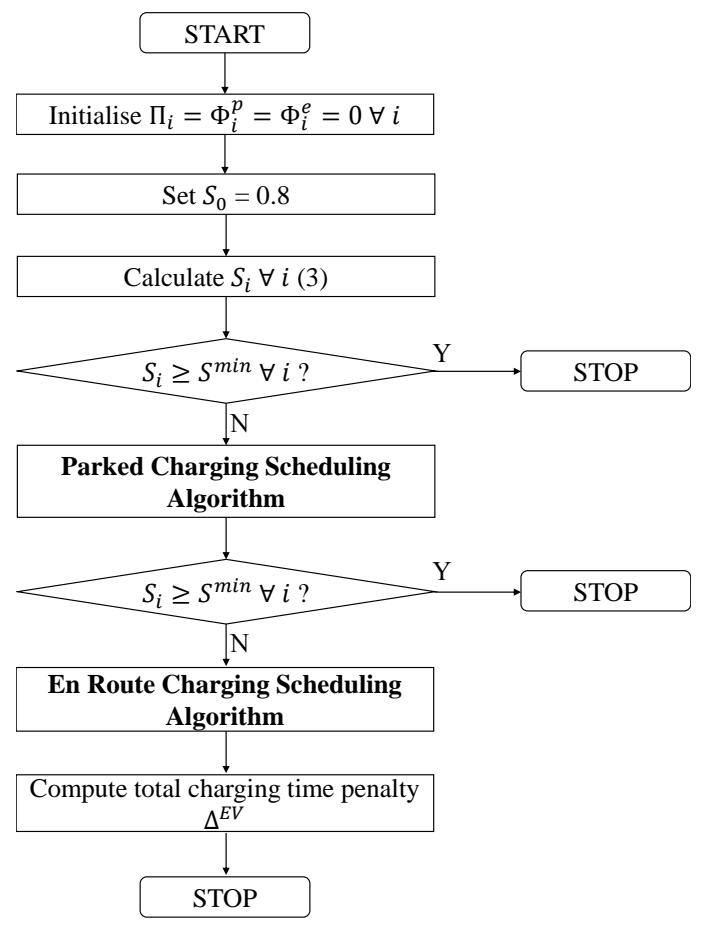

Figure 4: Flowchart showing heuristic method to derive idealised charging schedule given UK National Travel Survey travel diary and hence compute time penalty of charging

\subsection{Parked Charging}

\subsubsection{Parked Charging Scheduling Algorithm}

The parked charging scheduling algorithm is shown in Figure 5. It will first return a set $\mathbb{K}$ of trips which end with a parked charging opportunity. These are based on the destination of each trip and the level of access to parked charging that the vehicle is assumed to have (section 2.2.3). $\mathbb{K}$ contains the indices of the trips where parked charging is possible; for example, if parked charging is possible at the end of the first, fourth and fifth trips then $\mathbb{K}=\{1,4,5\}$. For cases where the vehicle does not have access to any charging at the locations present in the destinations of trips in the travel 
diary, $\mathbb{K}$ will be an empty set and hence no parked charging events can be scheduled.

The algorithm will loop through each trip $i$. If $S_{i}<S^{\text {min }}$, then it will seek to schedule the minimum number of parked charging events before trip $i$ such that:

1. The SoC after trip $i$ is greater than or equal to the minimum permissible, i.e. $S_{i} \geq S^{\text {min }}$.

2. In a set of possible parked charging events in $\mathbb{K}$ before trip $i$, the one that delivers the greatest increase to $S_{i}$ is chosen.

A flag variable $Q$ is initially set to $Z_{i}(5)$ and used to track whether taking a parked charging opportunity will lead to an improvement in $S_{i}$.

For each parked charging opportunity $k$ in $\mathbb{K}$ that is before trip $i$, the potential SoC gain $\Phi_{k}^{p}$ from that opportunity is calculated. To evaluate the effect of taking a parked charging opportunity after trip $k$ on the SoC following trip $i$, the decision variable is set $\Pi_{k}=1$ and all other decision variables whose indices are within $\mathbb{K}$ are set to zero. The resulting value of $S_{i}$ is copied as $F_{i}$ and stored in $\mathbb{S}$, the set of potential values of $S_{i}$ resulting from all possible parked charging opportunities before trip $i$.

This process is repeated until all possible parked charging events before $i$ are trialled. If the maximum element in set $\mathbb{S}$ is greater than $Q$, then taking parking opportunity after trip $k$ such that $F_{k}=\max (\mathbb{S})$ will offer the best improvement to the SoC after trip $i$ out of any of those possible. In this case, the vehicle will charge while parked at the end of trip $k$, and the corresponding decision variable is set $\Pi_{k}=1$. Once a parked charging event is chosen, it is removed from $\mathbb{K}$. $S_{i}$ is updated for all trips and $Q$ is set to $S_{i}$. This process is repeated until either $S_{i} \geq S^{\text {min }}$ or adding more parked charging events brings no improvement to $S_{i}$ (i.e. $\max (\mathbb{S}) \leq Q$ ). 


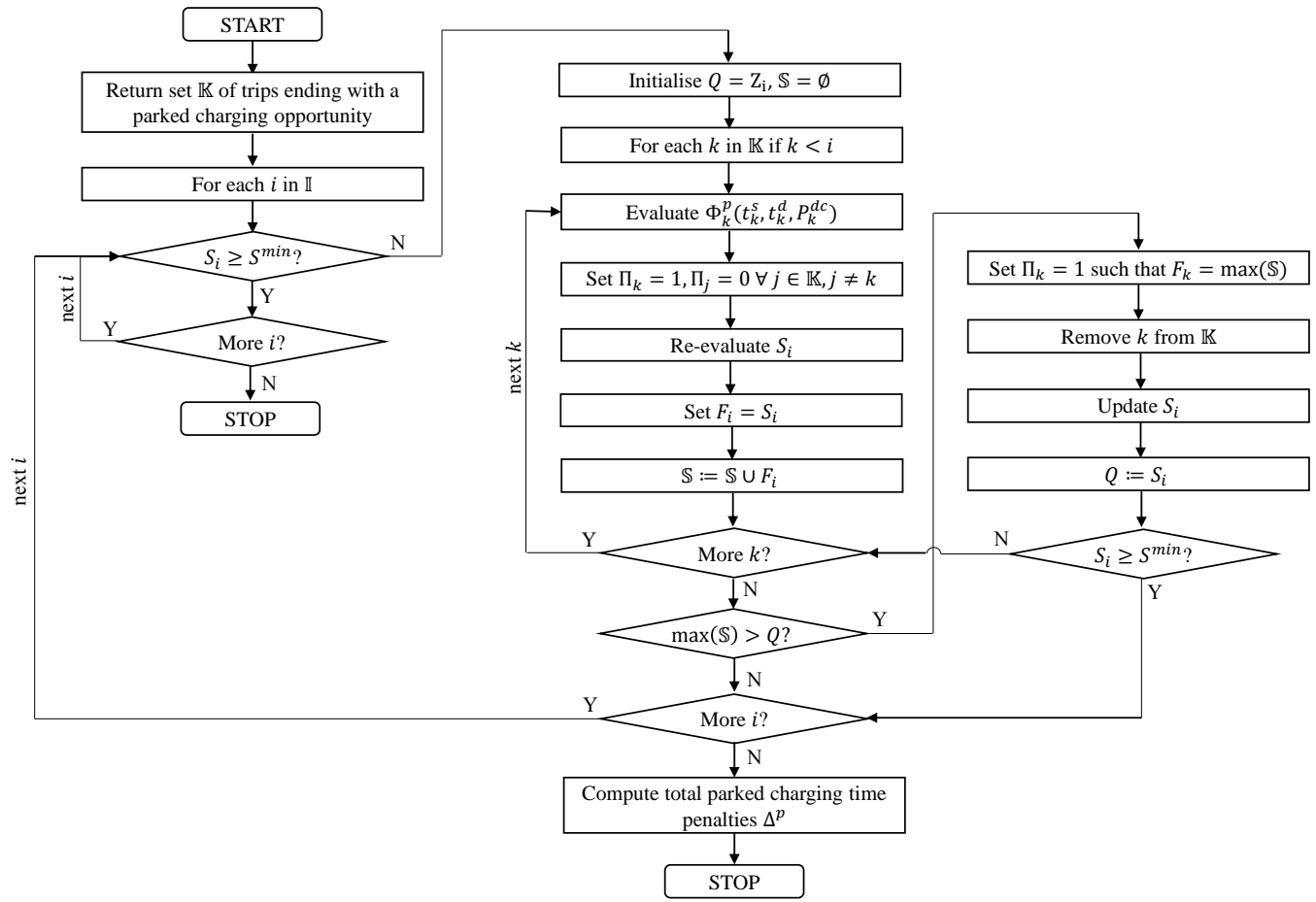

Figure 5: Flowchart showing parked charging scheduling algorithm

\subsubsection{Lithium Ion Charging Profile}

Parked charging is governed by a standard Constant Current - Constant Voltage (CC-CV) lithium ion battery charging curve [35-40] consisting of a constant current $(\mathrm{CC})$ stage in which the vehicle can receive full power until its $\mathrm{SoC}$ reaches 0.8 (taken from the real charging profile of an ABB EV charger presented in [37]), followed by a constant voltage (CV) phase during which the charging power exponentially decays to zero as the SoC tends to 1 . Charging power level can be expressed as a 'C-rate', i.e. the ratio of power of charging $(\mathrm{kW})$ to the battery capacity $(\mathrm{kWh})$. Figure 6 shows the charging power and SoC versus time for a battery charged at four different C-rates. 


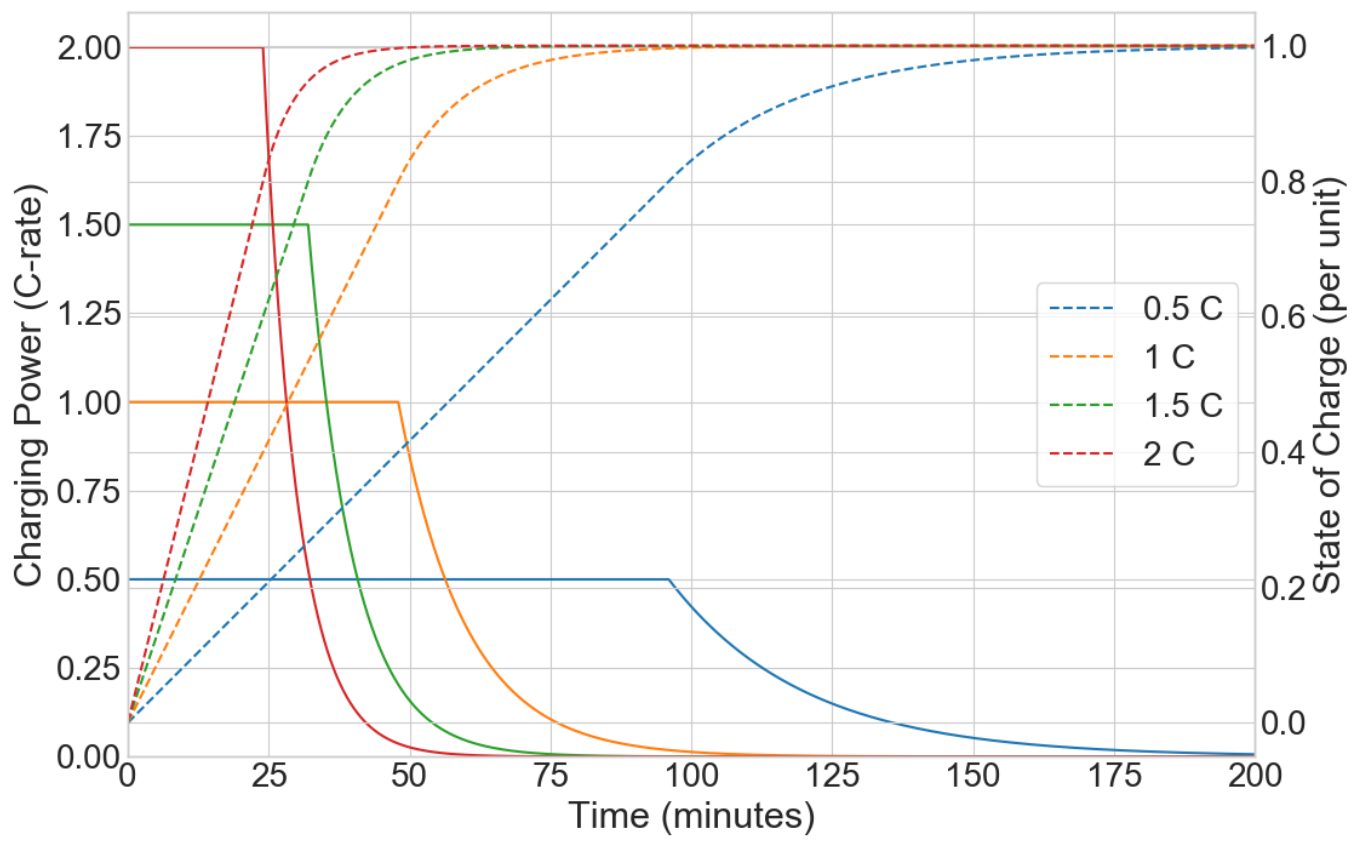

Figure 6: Battery charging profile for lithium ion batteries used for simulation of charging while parked - solid lines show applied power, dashed lines show battery SoC

The charging power $(\mathrm{kW})$ of the potential parked charging event following trip $i$ at time $t$ (hours) is related to time via the function in (6).

$$
P_{i}(t)= \begin{cases}P_{i}^{D C}, & t \leq t_{i}^{0.8} \\ P_{i}^{D C} e^{-\lambda_{i}\left(t-t_{i}^{0.8}\right)}, & t>t_{i}^{0.8}\end{cases}
$$

where $P_{i}^{D C}$ is the DC charging power $(\mathrm{kW})$ available at the potential parked charging event following trip $i, \lambda_{i}$ is the decay constant of the charger power of charging event $i$ in the $\mathrm{CV}$ region and $t_{i}^{0.8}$ is the time (hours) in the charging event following trip $i$ at which the battery's SoC reaches 0.8 and the charging event transitions from the $\mathrm{CC}$ region to the $\mathrm{CV}$ region.

$P_{i}^{D C}$ is equal to the corresponding $\mathrm{AC}$ charging power $P_{i}^{A C}$ (Table 1) multiplied by a one-way AC/DC converter efficiency $\eta$, set to 0.88 in accordance with empirical results presented in [36] (7) and $t_{i}^{0.8}$ is calculated via linear interpolation in (8).

$$
P_{i}^{D C}=\eta P_{i}^{A C}
$$




$$
t_{i}^{0.8}=\frac{\left(0.8-Z_{i}\right) C}{P_{i}^{D C}}+t_{i}^{s}
$$

The type of charging event $i$ is decided by the order of $t_{i}^{s}, t_{i}^{0.8}$ and $t_{i}^{d}$. The type of the charging event dictates how the resulting increase in SoC is calculated (sections 2.5.3-2.5.5).

\subsubsection{Increase in $S o C$ due to Constant Current (CC) Only Parked Charging Events}

If $t_{i}^{0.8}$ is greater than the parking end time $t_{i}^{d}$, the vehicle was not parked for sufficiently long to reach an SoC of 0.8 and the charging event is a CConly event. In this case, the increase in SoC from charged parking event $i$ is calculated as in (9).

$$
\Phi_{i}^{C C}=\frac{P_{i}^{D C}\left(t_{i}^{d}-t_{i}^{s}\right)}{C}
$$

\subsubsection{Increase in SoC due to Constant Current (CC) - Constant Voltage} (CV) Parked Charging Events

If $t_{i}^{d}$ is greater than the parking duration $t_{i}^{0.8}$, which in turn is greater than the charging event start time $t_{i}^{s}$, the vehicle will be charged in CC until it reaches $t_{i}^{0.8}$ and $\mathrm{CV}$ thereafter. To approximate the decay constant $\lambda_{i}$, the area under the curve between $t_{i}^{0.8}$ and $t_{i}^{\infty}$, the time at which the charging power reaches a value close to zero (taken as $1 \%$ of the maximum rated power $P_{i}^{D C}$ ), must be equal to $20 \%$ of the battery's capacity $C(10)$.

$$
\int_{t_{i}^{0.8}}^{t_{i}^{\infty}} P_{i}^{D C} e^{-\lambda_{i}\left(t-t_{i}^{0.8}\right)} d t=0.2 C
$$

After performing the integration and simplifying, an expression in terms of $\lambda_{i}$ and $t_{i}^{\infty}$ results in (11).

$$
P_{i}^{D C}\left(e^{-\lambda_{i}\left(t_{i}^{\infty}-t_{i}^{0.8}\right)}-1\right)+0.2 C \lambda_{i}=0
$$

For a given charging power, $\lambda_{i}$ and $t_{i}^{\infty}$ are approximated by the solution of a multivariate optimisation problem: to minimise the objective function expressed in (12) subject to the constraints in (13)-(15).

$$
f\left(\lambda_{i}, t_{i}^{\infty}\right)=P_{i}^{D C}\left(e^{-\lambda_{i}\left(t_{i}^{\infty}-t_{i}^{0.8}\right)}-1\right)+0.2 C \lambda_{i}
$$




$$
\begin{gathered}
f\left(\lambda_{i}, t_{i}^{\infty}\right) \geq 0 \\
\lambda_{i}, t_{i}^{\infty}>0 \\
e^{-\lambda_{i}\left(t_{i}^{\infty}-t_{i}^{0.8}\right)}<0.01
\end{gathered}
$$

The total energy transferred to the vehicle's battery in the CV region is found by evaluating the integral on the LHS of (10) between $t_{i}^{0.8}$ and $t_{i}^{\infty}$. This allows the calculation of the increase in SoC from a CC-CV parked charging event (16).

$$
\Phi_{i}^{C C-C V}=\frac{P_{i}^{D C}\left(t_{i}^{0.8}-t_{i}^{s}\right)+\frac{P_{i}^{D C}}{\lambda_{i}}\left(1-e^{-\lambda_{i}\left(t_{i}^{\infty}-t_{i}^{0.8}\right)}\right)}{C}
$$

\subsubsection{Increase in $S o C$ due to Constant Voltage (CV) Only Parked Charging Events}

If $t_{i}^{s}$ is greater than $t_{i}^{0.8}$, the vehicle began the charging event with an SoC above 0.8 . In this case, the total energy transferred to the vehicle's battery in the CV region is found by evaluating the integral on the LHS of (10) between $t_{i}^{s}$ and $t_{i}^{\infty}$. Simplifying, this gives the calculation of the increase in SoC from a CV-only parked charging event as (17).

$$
\Phi_{i}^{C V}=\frac{P_{i}^{D C}}{\lambda_{i} e^{-\lambda_{i} t_{i}^{0.8}}}\left(e^{-\lambda_{i} t_{i}^{s}}-e^{-\lambda_{i} t_{i}^{\infty}}\right)
$$

\subsubsection{Selection of SoC Increase Function}

The SoC increase function due to parked charging event $i$ is given by (18).

$$
\Phi_{i}^{p}= \begin{cases}\Phi_{i}^{C C}, & t_{i}^{s}<t_{i}^{d} \leq t_{i}^{0.8} \\ \Phi_{i}^{C C-C V}, & t_{i}^{s}<t_{i}^{0.8} \leq t_{i}^{d} \\ \Phi_{i}^{C V}, & t_{i}^{0.8} \leq t_{i}^{s}<t_{i}^{d}\end{cases}
$$

The time penalties due to parked charging $\delta_{i}^{p}$ (hours) for each trip $i$ in a vehicle's travel diary are found by (19).

$$
\delta_{i}^{p}= \begin{cases}\delta_{i}^{f p}, & \Pi_{i}=1 \\ 0, & \text { otherwise }\end{cases}
$$


where $\delta_{i}^{f p}$ is a fixed charging time penalty (hours) that depends on the location of charging (section 2.3).

\subsection{En Route Charging}

\subsubsection{En Route Charging Scheduling Algorithm}

En route charging events are scheduled only if $S_{i}<S^{\text {min }}$ for any trip following the scheduling of parked charging events as in section 2.5.1. The algorithm used for scheduling en route charge events is shown in Figure 7.

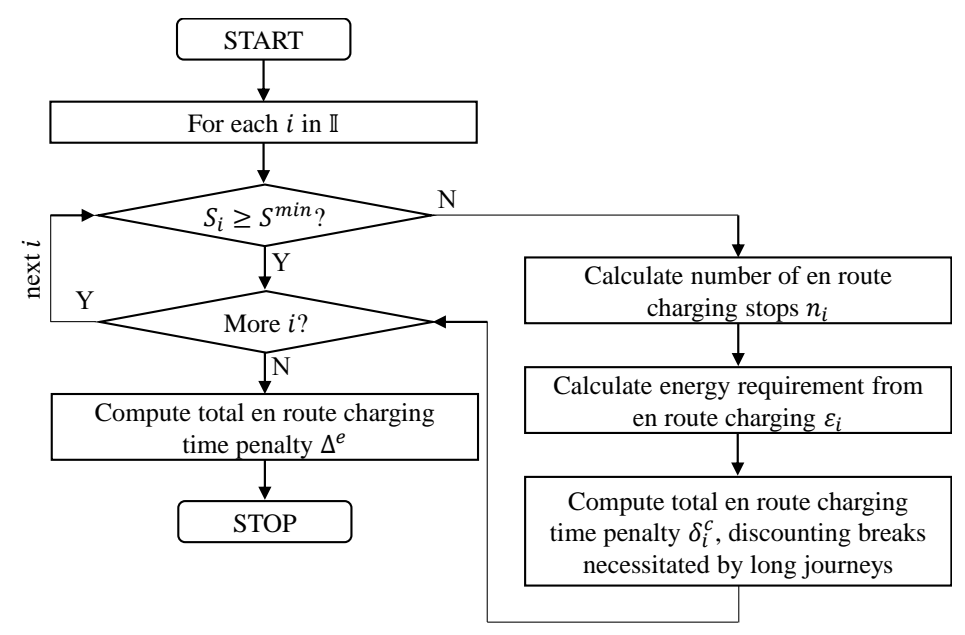

Figure 7: Flowchart showing en route charging scheduling algorithm

\subsubsection{Increase in SoC from En Route Charging Events}

Upon discovery of a trip for which $S_{i}<S^{\text {min }}$, the algorithm will calculate the number of necessary en route charging stops $n_{i}$ during that trip (20). The numerator in (20) represents the energy that the vehicle must attain in en route charging events to make it to the end of trip $i$ with an SoC equal to $S_{\text {min }}$. This is given by the energy requirement of trip $i$ minus the 'free energy' the vehicle has at the beginning of trip $i$, i.e. the difference between $S_{i-1}$ and $S^{\text {min }}$ multiplied by the battery capacity $C$. The denominator in (20) represents the maximum quantity of energy that can be taken by the vehicle in one charge: as charging from $80 \%$ to $100 \%$ SoC would take a disproportionately long time (section 2.5 ), the vehicle will stop charging when it reaches $80 \%$ SoC. It should be noted that while this assumption is valid for the CC-CV charging profile as shown in Figure 6, the advent of charging techniques such as the sinusoidal-ripple-current proposal in [41], the fuzzy 
multi-stage approach in [42], the SoC estimation method in [43] or the multistage CC-CV method in [44], has the potential to allow EVs to charge to SoCs above $80 \%$ in significantly less time than it would take for a typical $\mathrm{CC}-\mathrm{CV}$ regime such as in Figure 6. Under such a regime, the denominator in (20) would increase and drivers would be able to receive a greater amount of energy from a given en route charging session. The effect of this would be to reduce the level of charging inconvenience suffered by drivers, as they would have to make fewer stops.

$$
n_{i}= \begin{cases}\left\lceil\frac{E_{i}-\left(S_{i-1}-S^{\text {min }}\right) C}{\left(0.8-S^{\text {min }}\right) C}\right\rceil, & \text { if } E_{i}>\left(S_{i-1}-S^{\text {min }}\right) C \\ 0, & \text { otherwise }\end{cases}
$$

If trip $i$ does not present the vehicle with a parked charging opportunity, then it will charge more than is required for the current trip, up to a limit of $80 \%$ SoC on the final $\left(n_{i}^{t h}\right)$ en route charging session in trip $i$, so as to avoid having to charge immediately upon starting the next trip. Any further charging requirement until the next parked charging opportunity (denoted by trip $o$ in (21)) will be covered in subsequent trips. It follows that the energy requirement $\varepsilon_{i}$ for all en route charging sessions in trip $i$ is given by (21).

$$
\varepsilon_{i}= \begin{cases}\min \left\{n_{i}\left(0.8-S^{\text {min }}\right) C-\left(S_{i-1}-S^{\min }\right) C,\right. & \\ \left.\sum_{h=i}^{o} E_{h}-\left(S_{i-1}-S^{\text {min }}\right) C\right\}, & \text { if } n_{i} \geq 1 \\ 0, & \text { otherwise }\end{cases}
$$

The SoC increase due to all en route charging events in trip $i, \Phi_{i}^{e}$, is then given by $(22)$.

$$
\Phi_{i}^{e}=\frac{\varepsilon_{i}}{C}
$$

\subsubsection{Calculation of En Route Charging Time Penalties}

It follows that the time penalty $\delta_{i}^{e}$ (hours) endured by the vehicle from the en route charge events in trip $i$ is a sum of the fixed charging time penalties $\delta_{i}^{f e}$ (hours) associated with plugging in and removing the cable (section 2.3) and the total en route charging duration $\delta_{i}^{c}$ (hours) (23), which is adjusted to 
account for the presence of any natural breaks that would have been taken as part of long journeys as per section 1.3.4 (24).

$$
\begin{gathered}
\delta_{i}^{e}=n \delta_{i}^{f e}+\delta_{i}^{c} \\
\delta_{i}^{c}= \begin{cases}\frac{\varepsilon_{i}}{P^{e}}-0.25\left\lfloor\frac{T_{i}}{h}\right\rfloor, & \text { if } \frac{\varepsilon_{i}}{P^{e}}>0.25\left\lfloor\frac{T_{i}}{h}\right\rfloor \\
0, & \text { otherwise }\end{cases}
\end{gathered}
$$

where $P^{e}$ is the en route charging power available, depending on the battery capacity and charging power scenario (Table 1 ), and $h$ is the number of hours' driving before a 15 minute (or 0.25 hour) break is necessitated. In the UK Highway Code compliant scenario, $h=2$. In the sensitivity case, $h=4$.

\subsection{Boundary Conditions}

As mentioned in section 1.3.3, the EV must finish its travel diary with an $\mathrm{SoC}$ of 0.8 , so as to have replenished all the energy it expended through making the series of trips. If the travel diary's final trip represents a charging opportunity, then a fixed time penalty associated with plugging in and removing the cable is applied according to the type of parked charging event it is (Table 3). If not, then the parked charging scheduling algorithm (section 2.5 ) is run to find the minimum number of parked charging events such that the final $\mathrm{SoC}$ is at least 0.8 . If it is still below 0.8 , then an en route charging session must be scheduled (section 2.6) and the corresponding time penalties are added to the vehicle's total.

\subsection{Total EV Charging Time Penalty}

The total charging time penalty seen by an EV given a travel diary $\Delta^{E V}$ is given by $(25)$.

$$
\Delta^{E V}=\sum_{i \in \mathbb{I}}\left(\delta_{i}^{e}+\delta_{i}^{p}\right)
$$

The results presented in section 3 are normalised by the total driving time in the vehicle's travel diary to give $\hat{\Delta}^{E V}$ in minutes time penalty per hour of driving time, hence allowing easier comparison across the spectrum of driving behaviours (26).

$$
\hat{\Delta}^{E V}=\frac{60 \Delta^{E V}}{\sum_{i \in \mathbb{I}} T_{i}}
$$




\subsection{Comparison to ICEV Fuelling}

\subsubsection{Overview}

An ICEV's fuelling time penalty is equal to a fixed time penalty associated with a fuelling action from a minimum fuel level (at which the vehicle's remaining range is $25 \mathrm{~km}$ ) to a full tank multiplied by the amount of fuel the vehicle consumes during the week as a proportion of a the fuel tank's usable space.

\subsubsection{Fixed Fuelling Time Penalty}

Two ICEVs were used for the comparative analysis to represent a likely spread of the expected time penalty of ICEV fuelling; the 2018 Fiat 500 1.4L petrol, a small 'city' car with a 40 litre fuel tank and a fuel economy of 11.9/12.8/14.0 km/1 (city/combined/highway) and the 2018 Kia Sorento 2.4L petrol, a larger, longer-range vehicle with a 71 litre fuel tank and a fuel economy of 8.9/9.4/10.6 km/1 (city/combined/highway). As for the EV analysis, the fuel economy data was taken from the US Environmental Protection Agency's fuel economy test data [3].

The time penalty of a fuelling stop was fixed, based on the observed time taken for $50 \mathrm{ICEVs}$ visiting a petrol station in Glasgow, UK. The total time to visit the petrol station was taken as the time between stopping at the pump and leaving the pump after refuelling. Figure 8 shows histograms and CDFs for the time taken to refuel an ICEV, the time taken to pay for the fuel either in the shop or at the pump and the total time between arriving at the pump and leaving again after refuelling, including any walking between the car, pump and shop.
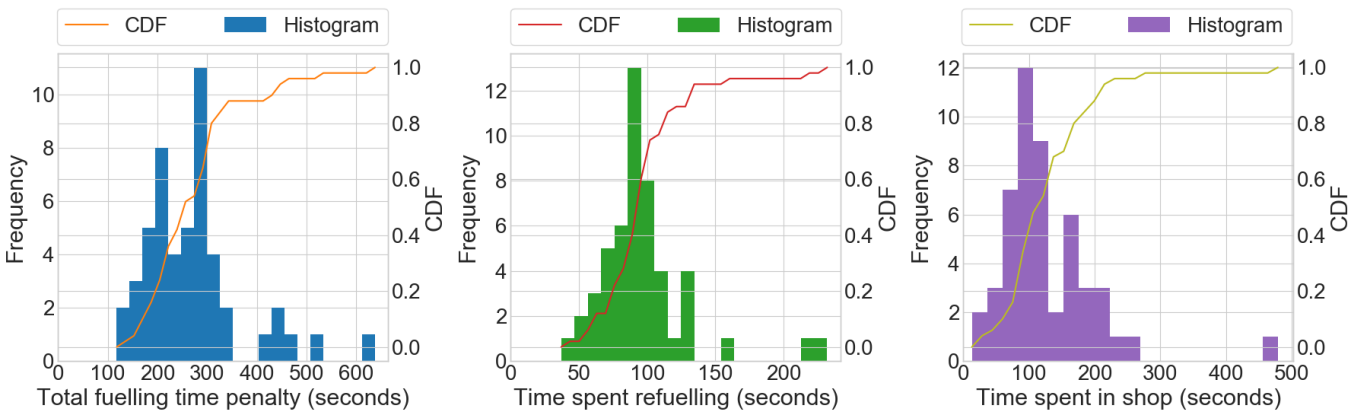

Figure 8: Probability distributions of time taken to refuel ICEV at a petrol station, comprising of time taken to refuel and time taken for fuel payment 
It was found that the mean time taken to refuel an ICEV was 271 seconds, comprised of 97 seconds pumping fuel into the vehicle, 126 seconds paying for the fuel either in the shop or at the pump and the remaining 48 seconds walking between the car, pump and shop. As could be expected, Figure 8 shows a greater variation in the time spent paying for the fuel than in the time spent actually fuelling the vehicle, likely because customers could have been buying other items or subject to a queue within the shop.

Due to its considerably larger fuel tank size, the Kia Sorento is subject to fewer petrol station stops than the Fiat 500. To establish a spread of expected petrol station time penalties, the best case is represented by the Kia Sorento with a fuelling time penalty of 207 seconds and the worst case is represented by the Fiat 500 with a fuelling time penalty of 294 seconds, representing the $25^{t h}$ and $75^{t h}$ percentiles respectively of the total time spent at the petrol station (Figure 8). Note that although these time penalties are given in seconds, they are converted to hours for all equations presented in this paper.

Although the time taken for the driver to get out of and re-enter the vehicle is not included in the fixed EV charging time penalties (section 2.3), it is included in the ICEV fuelling time penalty. This is based on the assumption that, unlike in a parked EV charging event, the driver is not leaving the car for any other reason than to refuel. Furthermore, unlike an en route EV charging event, the time taken to exit and re-enter the vehicle is not negligible in comparison to the total fuelling time penalty. It is assumed that the time spent driving up to the petrol pump or the EV charge point is common to both ICEV fuelling and EV charging and would vary based on the specific EV charging station or petrol station: thus, it is not included in either case.

\subsubsection{Calculation of Time Penalty from ICEV Fuelling Given a Travel Diary} from the UK National Travel Survey

For each trip $i$ in the travel diary, the fuel requirement $f_{i}(1)$ is $(27)$.

$$
f_{i}=\frac{d_{i}}{\epsilon_{i}}
$$

where $d_{i}$ and $\epsilon_{i}$ are the distance $(\mathrm{km})$ and fuel economy $(\mathrm{km} / \mathrm{l})$ of each trip. The fuel economy levels (city/combined/highway) are set by trip according to the same speed thresholds as in the EV analysis (section 2.4.2).

The minimum level of fuel the vehicle $f^{\text {min }}$ is permitted is the amount of fuel that would deliver the prescribed minimum range $r^{\text {min }}$ of $25 \mathrm{~km}$ based 
on the combined fuel economy $\epsilon^{c}(28)$, as analogous to the EV analysis (4).

$$
f^{\min }=\frac{r^{\min }}{\epsilon^{c}}
$$

The time penalty $\delta_{i}^{I C E V}$ (hours) associated with trip $i$ is then the fixed fuelling time penalty $\delta^{\text {fuel }}$ (hours) multiplied by the fuel requirement $f_{i}$ as a proportion of the usable fuel tank space (given between the difference between the tank size $V(\mathrm{l})$ and the minimum fuel $\left.f^{\min }\right)$. As with the EV analysis, any natural breaks taken as a result of long journeys are accounted for (29).

$$
\delta_{i}^{I C E V}= \begin{cases}\delta^{\text {fuel }} \frac{f_{i}}{V-f^{\min }}-0.25\left\lfloor\frac{T_{i}}{h}\right\rfloor, & \text { if } \delta^{\text {fuel }} \frac{f_{i}}{V-f^{\min }}>0.25\left\lfloor\frac{T_{i}}{h}\right\rfloor \\ 0, & \text { otherwise }\end{cases}
$$

As the time penalty of fuelling an ICEV is much shorter and the ranges of the vehicles are longer, there is no reported difference in the resulting fuelling time penalty between the Highway Code compliant case and the sensitivity case.

The total fuelling time penalty over the course of a travel diary $\triangle^{I C E V}$ is then the sum of the fuelling time penalties over the set of trips $\mathbb{I}$ (30) which, as in the EV analysis, is normalised by the total time spent driving to give $\hat{\Delta}^{I C E V}(31)$.

$$
\begin{aligned}
& \Delta^{I C E V}=\sum_{i \in \mathbb{I}} \delta_{i}^{I C E V} \\
& \hat{\Delta}^{I C E V}=\frac{60 \Delta^{I C E V}}{\sum_{i \in \mathbb{I}} T_{i}}
\end{aligned}
$$

\section{Results}

\subsection{Total Charging Time Penalty per Driving Time}

\subsubsection{Cumulative Distribution Functions}

Due to the significant variation in the duration and distance of journeys made across the 39,020 travel diaries for which charging schedules are derived, results are presented in the form of cumulative distribution functions (CDFs) in Figures 9-12 for four scenarios relating to the charging power available 
(section 2.2.2) and the breaks taken during long journeys scenario (section 1.3.4). Each figure shows a plot for each battery capacity trialled. In all plots, the vertical axis shows the proportion of travel diaries whose total normalised charging time penalty (minutes per hour driving) is less than or equal to the corresponding horizontal axis value. Two lines are shown on each plot for a direct comparison to the fuelling time penalty endured by ICEVs for the 'worst case' (Fiat 500, $75^{\text {th }}$ quartile refuel time) and the 'best case' (Kia Sorento, $25^{\text {th }}$ quartile refuel time) (section 2.9). The level of charging access is given in the legends: $\mathrm{H}, \mathrm{W}$ and $\mathrm{P}$ represent access to home, work and public destination charging respectively and a $\neg$ symbol preceding any letter represents lack of access to charging at that location. The horizontal axes are limited to values below 5 minutes' charging time penalty per hour driving to enable clarity for lower charging time penalties. 


\section{LOW POWER SCENARIO, 15 MINS BREAK / 2 HOURS DRIVING}
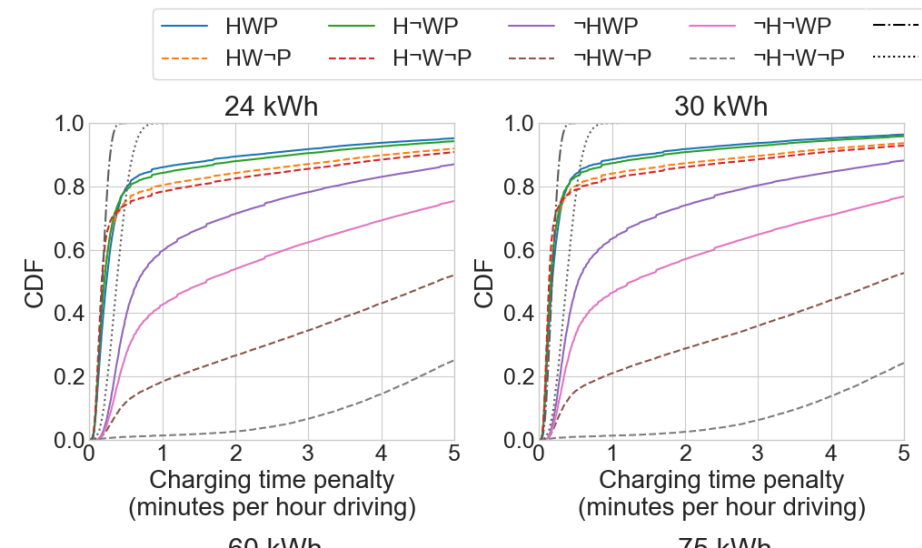

-..- Kia Sorento - Q25 refuel time
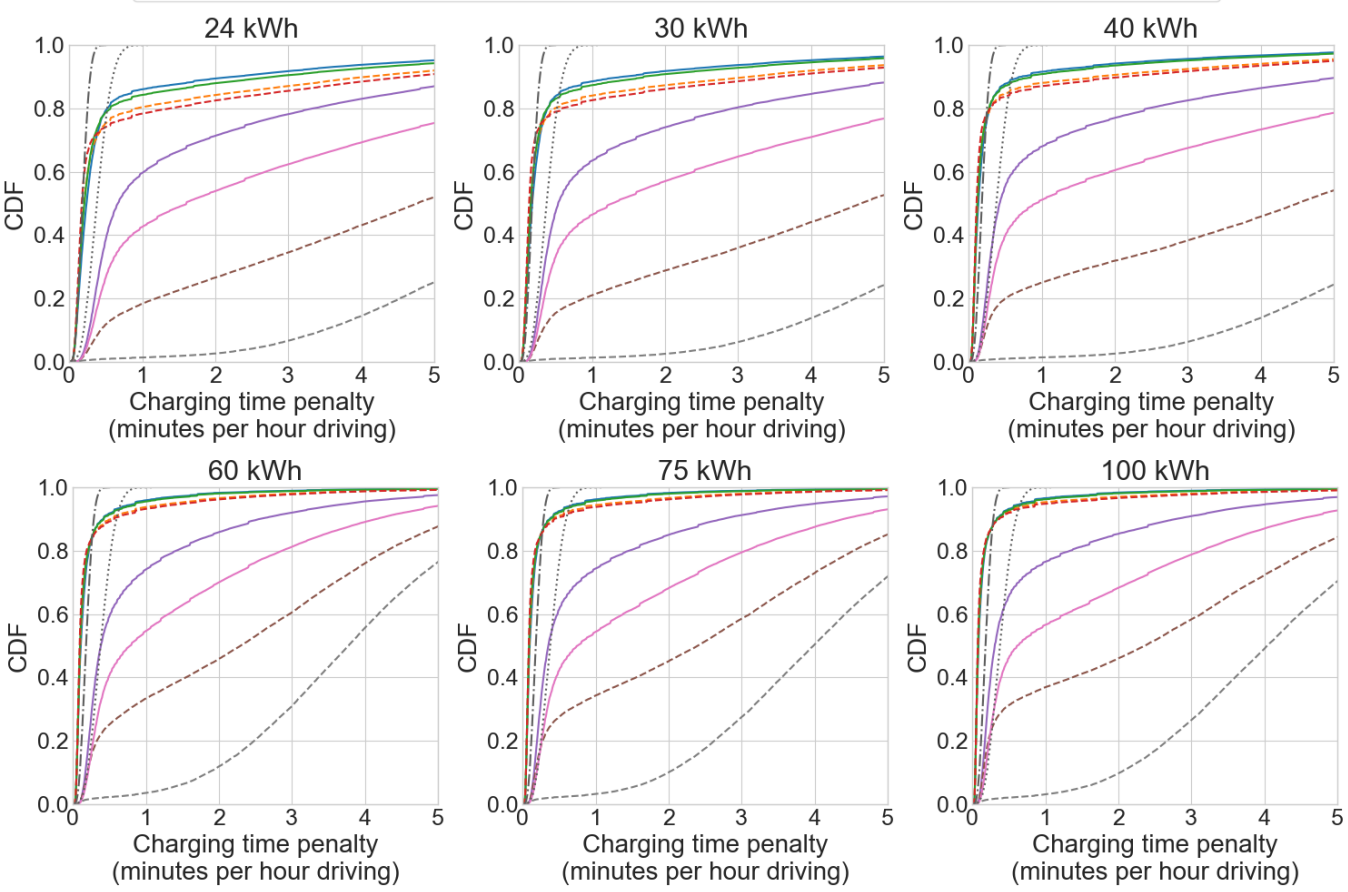

Figure 9: Cumulative distribution functions of normalised charging time penalty (minutes per hour driving) for various battery capacities and levels of charging access - low power scenario, UK Highway Code compliant case (15 minutes' break per 2 hours' driving) 


\section{LOW POWER SCENARIO, 15 MINS BREAK / 4 HOURS DRIVING}

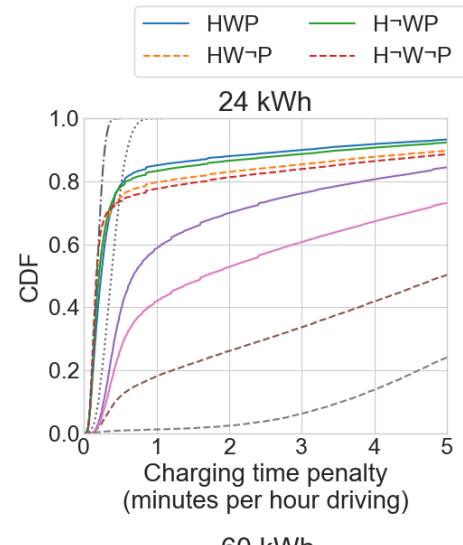

$\begin{array}{ll}- & \neg H W P \\ ----- & \neg H W \neg P\end{array}$

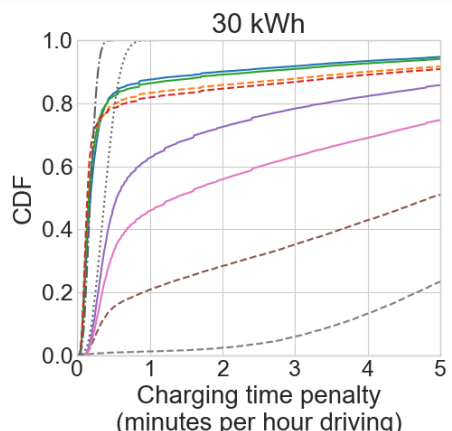

(minutes per hour driving)

\section{$75 \mathrm{kWh}$}

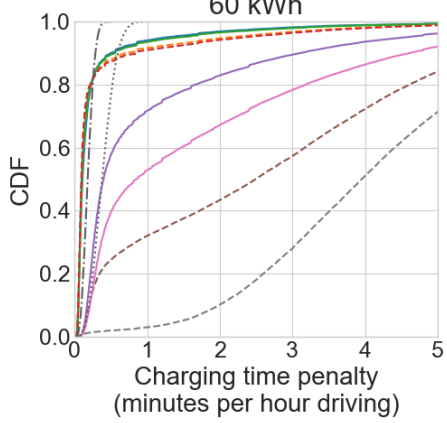

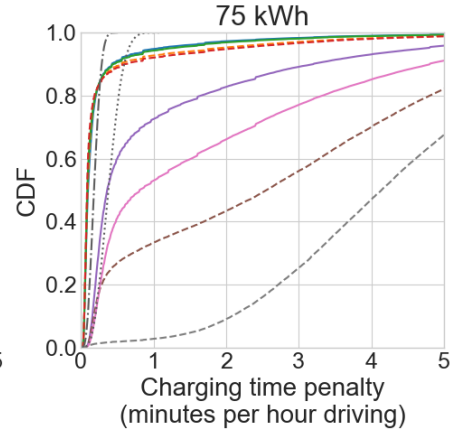

-.- Kia Sorento - Q25 refuel time Fiat 500 - Q75 refuel time

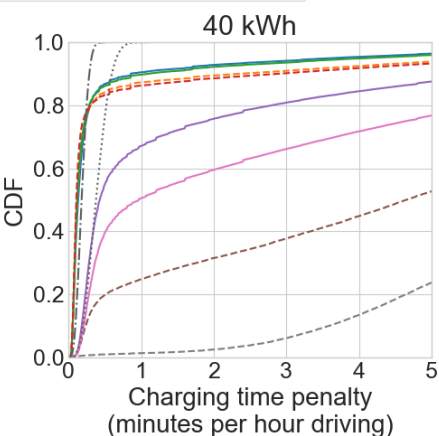

$100 \mathrm{kWh}$

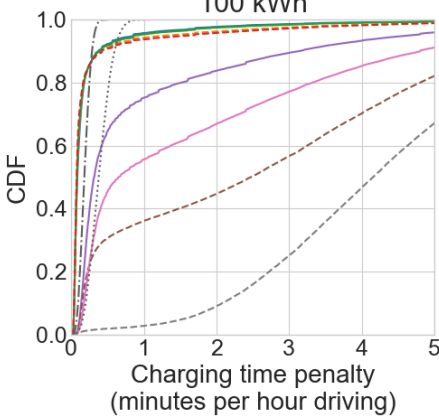

Figure 10: Cumulative distribution functions of normalised charging time penalty (minutes per hour driving) for various battery capacities and levels of charging access - low power scenario, sensitivity case (15 minutes' break per 4 hours' driving) 
HIGH POWER SCENARIO, 15 MINS BREAK / 2 HOURS DRIVING

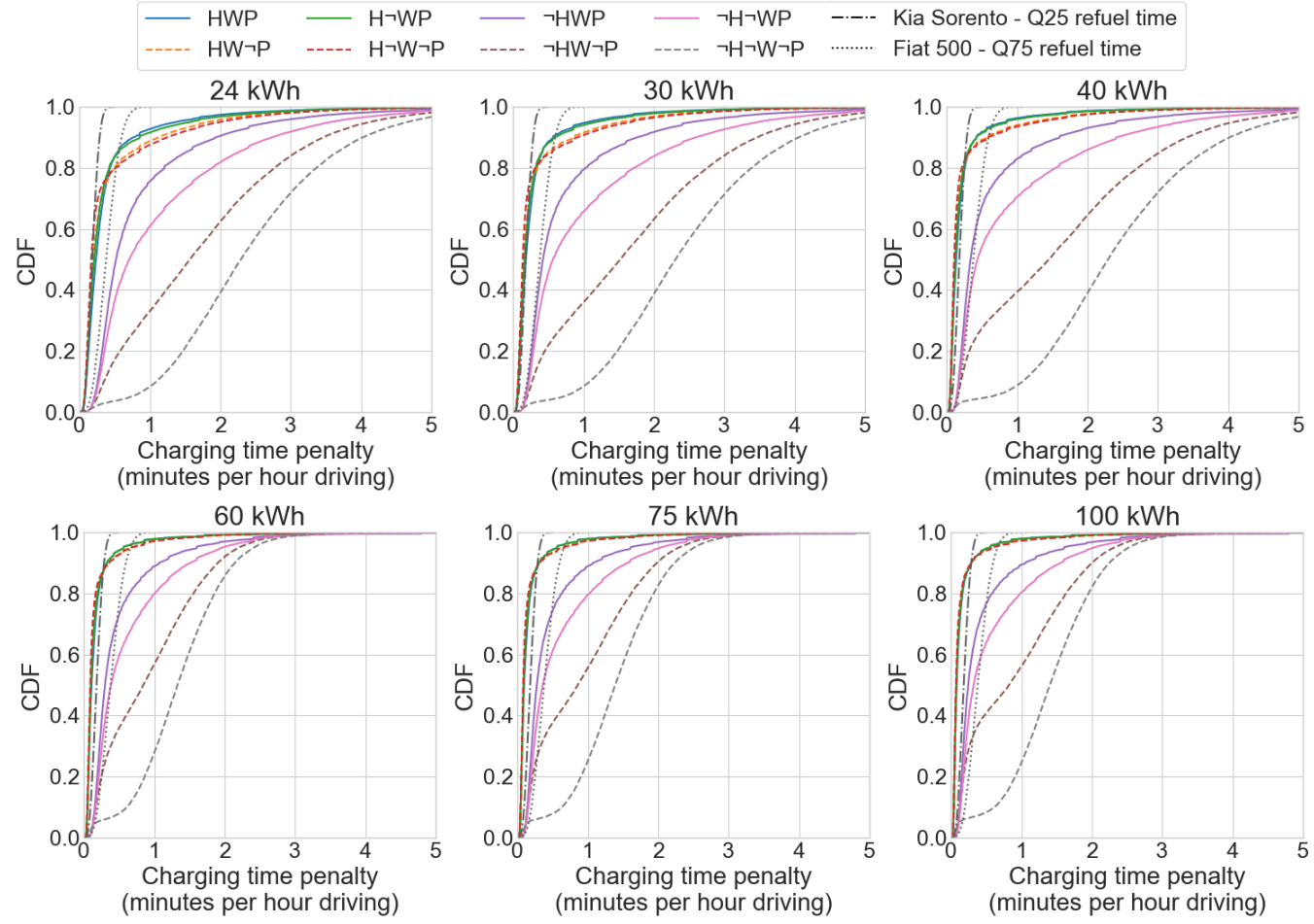

Figure 11: Cumulative distribution functions of normalised charging time penalty (minutes per hour driving) for various battery capacities and levels of charging access - high power scenario, sensitivity case (15 minutes' break per 2 hours' driving) 
HIGH POWER SCENARIO, 15 MINS BREAK / 4 HOURS DRIVING

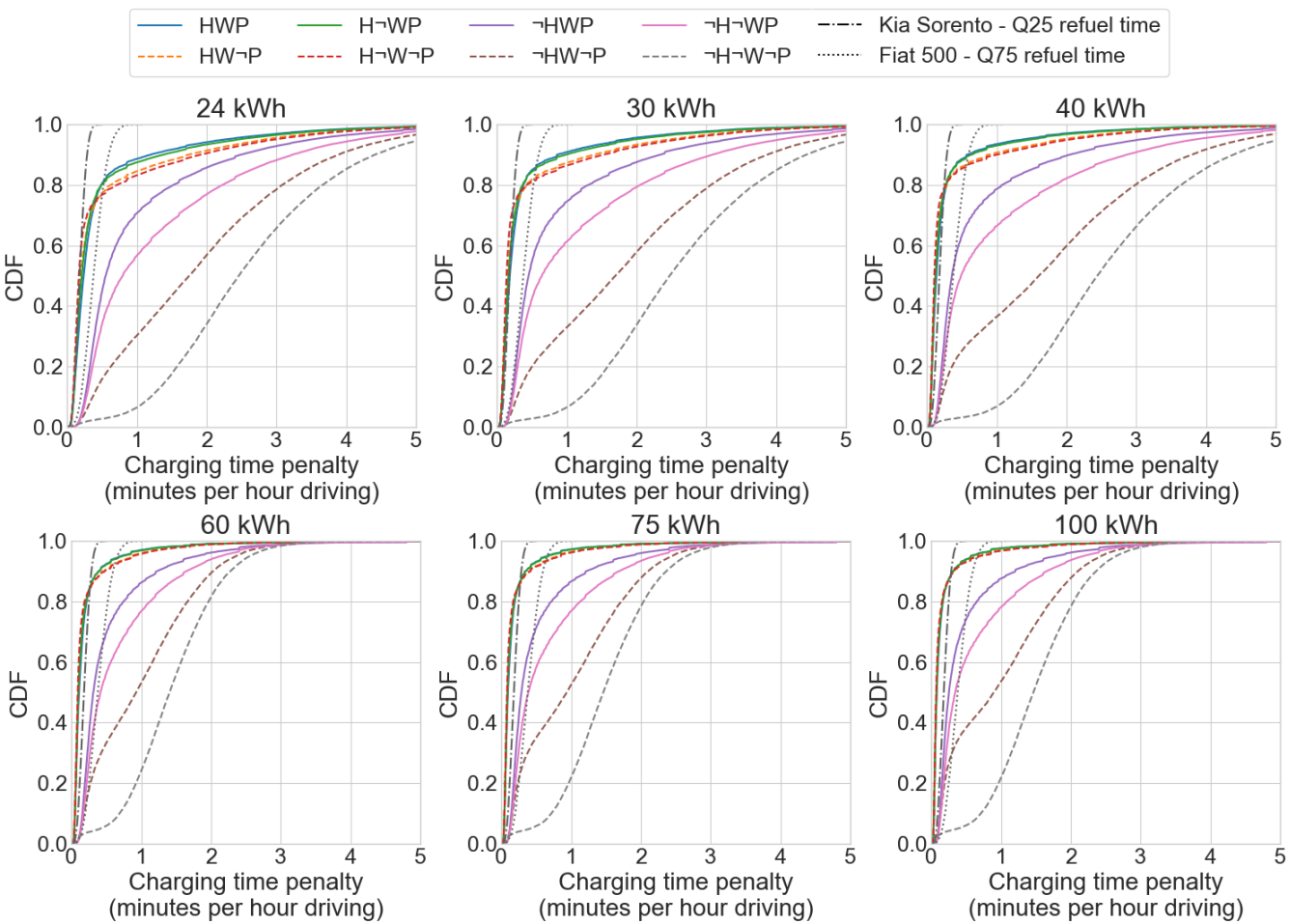

Figure 12: Cumulative distribution functions of normalised charging time penalty (minutes per hour driving) for various battery capacities and levels of charging access - high power scenario, sensitivity case (15 minutes' break per 4 hours' driving)

Despite the normalisation of the results in terms of charging time penalty per driving time, Figures 9-12 show a significant variation in the total charging time penalty per driving time experienced by would-be EV drivers using the synthesised NTS travel diaries. This is due to the variation in the type of journeys individuals are making, particularly in terms of distance (and therefore energy requirement) and the frequency and duration of parking opportunities between journeys. The variation in EV charging time penalty is shown to be significantly greater than the variation in ICEV fuelling time penalty. This is due to the different types of time penalties involved; where drivers are forced to charge en route, their time penalty is much greater than if they are not.

Having access to charging at more locations is shown to significantly reduce the time penalty that an EV driver will expect to endure, with access 
to home charging being far more useful for minimising the total time penalty than workplace or public destination charging. Consider the results for the low power charging scenario/Highway Code Rule 91 compliant case with 24 kWh batteries as an example (the top-left plot in Figure 9): while only a small proportion $(1.31 \%)$ of EVs that rely solely on en route charging $(\neg \mathrm{H} \neg \mathrm{W} \neg \mathrm{P})$ would endure a charging time penalty of a minute or less per hour of driving, this is increased to $78.3 \%$ for EVs who have access to charging at home but nowhere else $(\mathrm{H} \neg \mathrm{W} \neg \mathrm{P})$ and $86.0 \%$ for $\mathrm{EVs}$ who have access to charging at all three options (HWP).

Increasing the battery capacity also offers a dramatic reduction in time penalty, providing the vehicle has some level of access to parked charging. Considering the same set of results (Figure 9), the $78.3 \%$ of EVs with 24 $\mathrm{kWh}$ batteries and $\mathrm{H} \neg \mathrm{W} \neg \mathrm{P}$ access to charging that expect to endure less than a minute of charging time penalty per hour driving becomes $87.0 \%$ for $40 \mathrm{kWh}$ batteries and $94.8 \%$ for $100 \mathrm{kWh}$ batteries; the $86.0 \%$ of EVs with 24 $\mathrm{kWh}$ batteries and HWP access to charging that expect to endure less than a minute of charging time penalty per hour driving becomes $91.6 \%$ for $40 \mathrm{kWh}$ batteries and $96.6 \%$ for $100 \mathrm{kWh}$ batteries. For individuals who solely rely on en route charging, the effect of increasing the battery size (and therefore the range), results in fewer stops and therefore fewer fixed time penalties. However, the expended energy must still be recouped after the travel diary so the time penalty associated with en route charging itself must be the same for a given charging power. The result is a very slight increase in the proportion of EVs that expect to endure a charging time penalty of a minute or less per hour of driving from $24 \mathrm{kWh}(1.31 \%)$ to $40 \mathrm{kWh}(1.34 \%)$, and a larger increase for when vehicles have access to higher charger power, as they are assumed to for capacities of $60 \mathrm{kWh}$ and over (Table 1) - accordingly, $3.1 \%$ of EVs with $100 \mathrm{kWh}$ batteries are expected to endure a charging time penalty of a minute or less per hour of driving.

By comparing Figures 9 and 11, the effect of charging power is shown for the UK Highway Code compliant assumption. The result of increasing charging power from the low to high power scenario is a reduction in time penalty for all use cases, though a much greater reduction for those without access to charging at home due to the greater increases in charging power as a result of moving from the low to high power charging scenarios (Table 1) and the fact that EV users who lack access to charging at home are more likely to be forced to rely on en route charging to a greater extent, something which carries a time penalty associated with the charging itself, which is inversely 
proportional to the charger power available. For example, while $20.9 \%$ of $30 \mathrm{kWh}$ EVs would experience a charging time penalty of a minute or less with $\neg \mathrm{HW} \neg \mathrm{P}$ under the low power scenario, $35.9 \%$ of the same EVs would experience the same time penalty or less under the high power scenario.

The effect of increasing charging power is greater for those with higher time penalties than it is for those with lower time penalties. This is because those with higher penalties are increasingly dominated by en route charging which, as already mentioned, carries a time penalty inversely proportional to the charging power. This can be seen by comparing Figures 9 and 11; whereas in the low power scenario there remains a small proportion of EVs with 24,30 or $40 \mathrm{kWh}$ batteries with access to charging at home who are expected to endure a time penalty of greater than 5 minutes per hour of driving, for the high power charging scenario virtually $100 \%$ of EVs of all battery sizes can expect to endure a charging time penalty of less than 3 minutes per hour of driving.

By comparing Figure 9 with Figure 10 and Figure 11 with Figure 12, the effect of moving from the Highway Code compliant case to the sensitivity case is to reduce the cumulative probabilities that a vehicle will experience a normalised time penalty under a certain value. Though slight, the effect is more pronounced at larger normalised time penalties, reflecting the fact that those more likely to endure greater time penalties (chiefly diaries with longer journeys and therefore a need to stop and charge en route) are more likely to be affected by this assumption.

\subsubsection{Convenience Parity between EVs and ICEVs}

'Convenience parity' is defined in this paper as the point — for a particular combination of battery capacity, charger power and level of access to charging - at which EV charging carries a comparable time penalty to ICEV fuelling. Convenience parity is shown in Figures 9-12 by the region where the coloured lines representing the time penalty endured by EVs under each case are between the black lines representing the best and worst cases for ICEV fuelling.

As suggested in section 1.1, there could be cases where EV charging is of greater convenience than ICEV fuelling, provided that parked charging opportunities (which have a smaller time penalty than ICEV fuelling events) are sufficiently plentiful such that the vehicle does not run out of range between them. This is indicated by the regions in Figures 9-12 by the coloured lines being to the left of the black lines: for example, in the low power, UK 
Highway Code compliant case (Figure 9), it is clear than approximately $80 \%$ of EVs with $40 \mathrm{kWh}$ batteries would expect less inconvenience than ICEV users if they had access to charging at home. This is a particularly significant result as $40 \mathrm{kWh}$ has recently established itself as a 'standard' battery capacity for EVs at the affordable end of the market (this is discussed further in section 4). The effect of charger power on the proportion of EVs that are likely to experience greater convenience than ICEVs is negligible. This is due to the fact that those with low time penalties are dominated by fixed time penalties associated with plugging in/removing cables and hence are not affected by charging power. It should be noted that there are no combinations of battery size and charger power that allow EVs without access to home charging greater convenience than ICEVs.

In the low power charging scenario for those with access to at least charging at home, in excess of $75 \%$ of travel diaries achieved convenience parity from battery sizes of $24 \mathrm{kWh}$, increasing to $85 \%$ for battery sizes of $40 \mathrm{kWh}$ and $90 \%$ for $60 \mathrm{kWh}$. Convenience parity is significantly more difficult to achieve without access to charging at home. The next best option is shown to be having access to charging at both work and public places. This enables convenience parity for approximately $50 \%$ of travel diaries with battery capacities of $40 \mathrm{kWh}$.

Increasing the charging power makes it easier for convenience parity to be achieved for those without access to charging at home; in a high power scenario, around $60 \%$ of $40 \mathrm{kWh}$ EVs with access to charging at work and public places can expect convenience parity with ICEVs. However, a sizeable proportion of EV drivers can still expect to see considerable inconvenience relative to ICEV drivers: even with large battery sizes, only a small proportion of travel diaries were able to achieve convenience parity between EVs and ICEVs.

A common factor to all plots in Figures 9-12 is the trend towards significantly larger time penalties expected for those who must rely solely on en route charging. Due to the boundary conditions assumption detailed in section 1.3.3, the time penalty expected by these individuals does not change with battery size, apart from the fact that the highest three battery sizes on trial are assumed to have access to a faster rate of charging (Table 1). An increase in charger power reduces the time penalty suffered by this group of individuals, though there is no combination of battery capacity or charger power that enables their convenience parity with ICEVs: due to the significant difference in the rate at which energy can be added to the vehicle based 
on current battery technology (as previously discussed in section 1.1), the use of an EV will remain considerably less convenient than the use of an ICEV unless the driver has some level of access to parked charging.

\subsection{Delay due to Charging During Long Journeys}

\subsubsection{Proportion of Trips Facing Delay due to Charging}

Figure 13 shows a histogram of all journeys in the NTS data by distance, with vertical lines to indicate the proportion of journeys that could not be completed on a single charge with at least $25 \mathrm{~km}$ range remaining, given the journeys' energy requirements and vehicles' energy consumption levels (Figure 3).

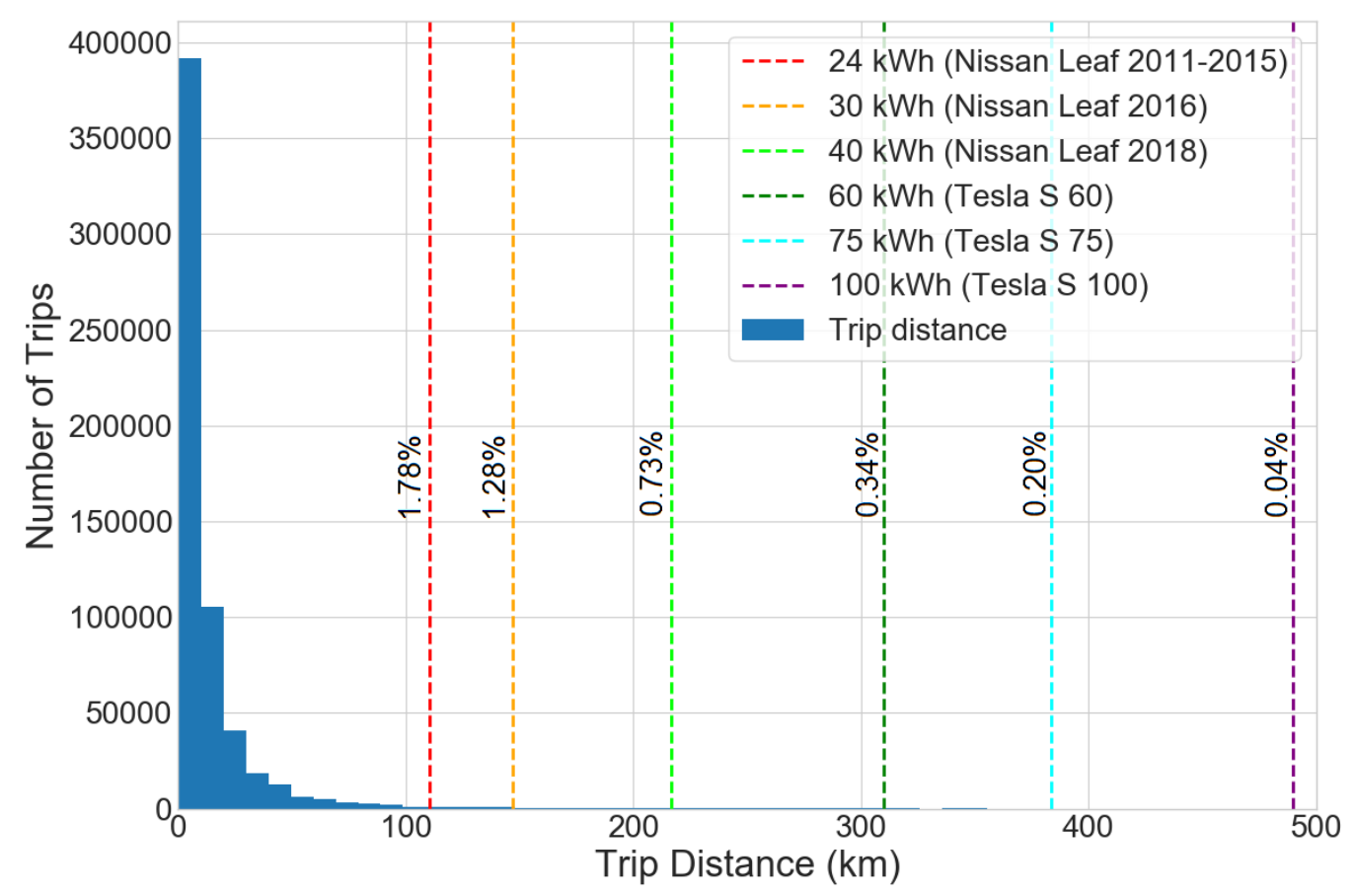

Figure 13: Histogram showing frequency of trips in NTS by distance with vertical lines indicating the proportion of trips that each vehicle modelled would not be able to complete on a single charge with at least $25 \mathrm{~km}$ range remaining

While the proportion of trips that are outside of the range of all vehicles considered could be stated as being relatively small, the perception that EV charging would cause an inconvenience during long journeys has already been discussed as a barrier preventing consumers switching their ICEVs for EVs. 
Figure 14 shows a breakdown of the proportion of trips which would face a delay from having to charge where the charging could not be fitted into the natural breaks taken during the journeys for varying battery capacities if it is assumed UK Highway Code Rule 91 is followed (left) and for the sensitivity case where drivers take breaks half as often as they are advised to (right). Note that for the analysis presented in this section, it is assumed that the vehicle starts each long journey with an SoC of 1.

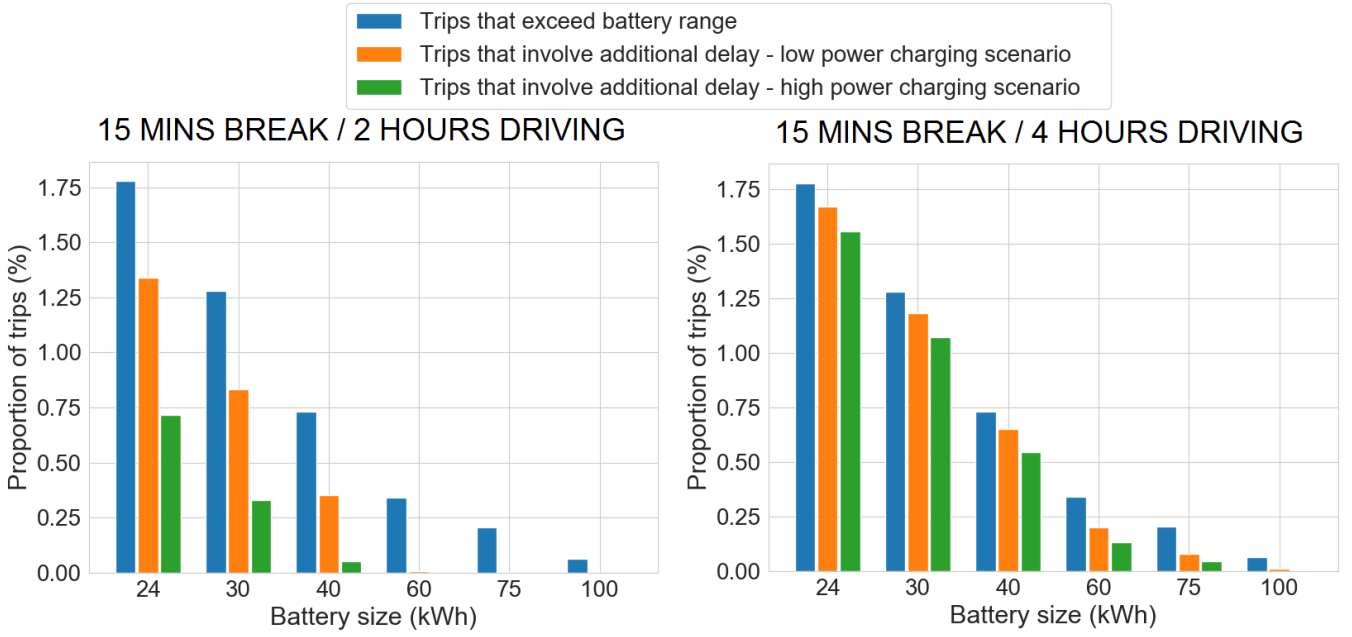

Figure 14: Proportion of trips facing delay for EVs with various battery sizes for low and high power charging scenarios - UK Highway Code Rule 91 case (left) and sensitivity case (right)

In Figure 14, the blue bars represent the vertical lines as on Figure 13 and the orange/green bars represent the proportion of journeys that would be delayed by charging over and above the delays for natural breaks. As shown by the difference between the orange and green bars, increasing the charging power available to the vehicle reduces the proportion of trips that incur a delay additional to that for natural breaks. Drivers who take fewer breaks than recommended by the Highway Code will experience more frequent additional delays for charging. Due to the higher charging power available for EVs with battery capacities of $60 \mathrm{kWh}$ and above, the proportional difference between the blue bars and other bars is greater for these larger battery sizes: for the case where drivers are compliant with the UK Highway Code, 0.007\% of journeys are expected to face delay due to charging for an EV with a 60 $\mathrm{kWh}$ battery for the low power charging scenario, that result being $0.0002 \%$ 
for the high power charging scenario. For the sensitivity case, this is significantly higher: $0.21 \%$ of journeys are expected to face a delay for the low power charging scenario and $0.12 \%$ of journeys are expected to face a delay under a high power charging scenario.

\subsubsection{Adjusted Journey Times due to Charging Delay}

Figure 15 presents probability distributions of the length of delay that EV drivers can expect on long journeys for different battery capacities for the low power (left) and high power (right) charging scenarios for both the Highway Code Rule 91 case (top) and the sensitivity case (bottom).

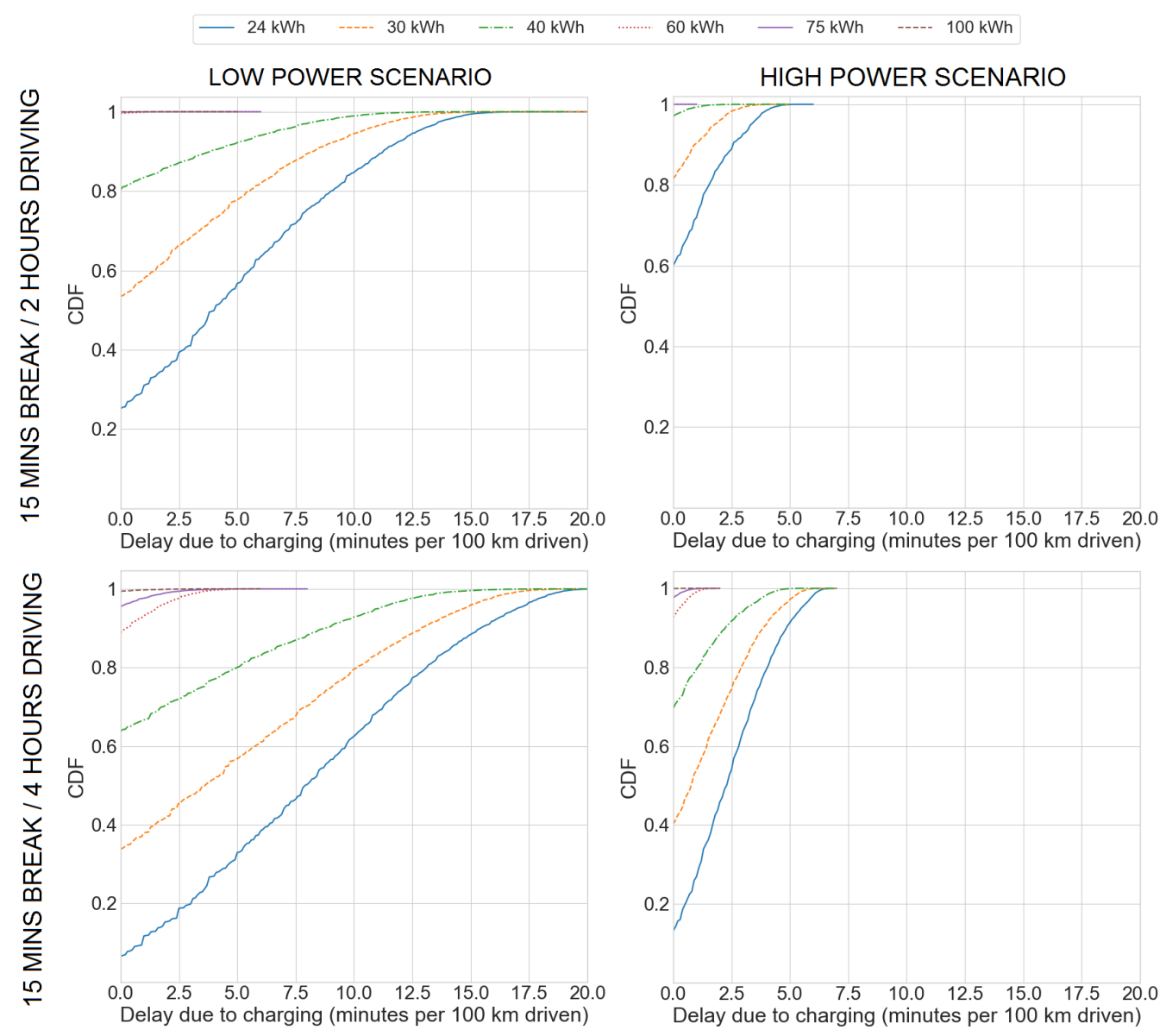

Figure 15: CDFs showing the length of delay due to charging per $100 \mathrm{~km}$ driving distance for various battery sizes for low power (left) and high power (right) charging scenarios for both the Highway Code Rule 91 case (top) and the sensitivity case (bottom) 
Figure 15 shows that on the occasions when delays do occur, their duration is linked to battery capacity and charging power. To consider the case where drivers are assumed to be compliant with the UK Highway Code: while approximately $45 \%$ of journeys with a $24 \mathrm{kWh}$ EV that faced a delay would experience a delay exceeding 5 minutes per $100 \mathrm{~km}$ driven, approximately $10 \%$ of journeys with a $40 \mathrm{kWh} \mathrm{EV}$ that faced a delay would face the same delay per $100 \mathrm{~km}$ driven for the low power charging scenario. Increasing the charging power is seen to have a significant effect on the expected delay, with fewer than $0.1 \%$ of the journeys that faced a delay (shown in Figure 14 to be approximately $0.7 \%$ of total journeys) facing a delay of over 5 minutes for a $24 \mathrm{kWh} \mathrm{EV}$. It is shown that in both charging scenarios, the delays faced by EVs with battery capacities of $60 \mathrm{kWh}$ and above are very small: it is argued that as these represent such a tiny proportion of overall journeys taken, convenience parity for long journeys occurs for battery capacities of 60 kWh and above. For the sensitivity case, a higher proportion of journeys are delayed and those delays are more likely to be longer. The $45 \%$ of journeys in which a $24 \mathrm{kWh}$ EV would face a delay of over 5 minutes per $100 \mathrm{~km}$ driven becomes $69 \%$ under the sensitivity case, and the $10 \%$ of journeys in which a $40 \mathrm{kWh}$ EV would face a delay of over 5 minutes per $100 \mathrm{~km}$ becomes $20 \%$ under the sensitivity case.

\subsection{Number of Infeasible Travel Diaries}

Figure 16 shows the proportion of NTS travel diaries that are rendered infeasible by the presence of en route charging, i.e. when the time penalty

attributed to en route charging in a given trip means that the arrival time would occur after the departure time of the subsequent trip. 


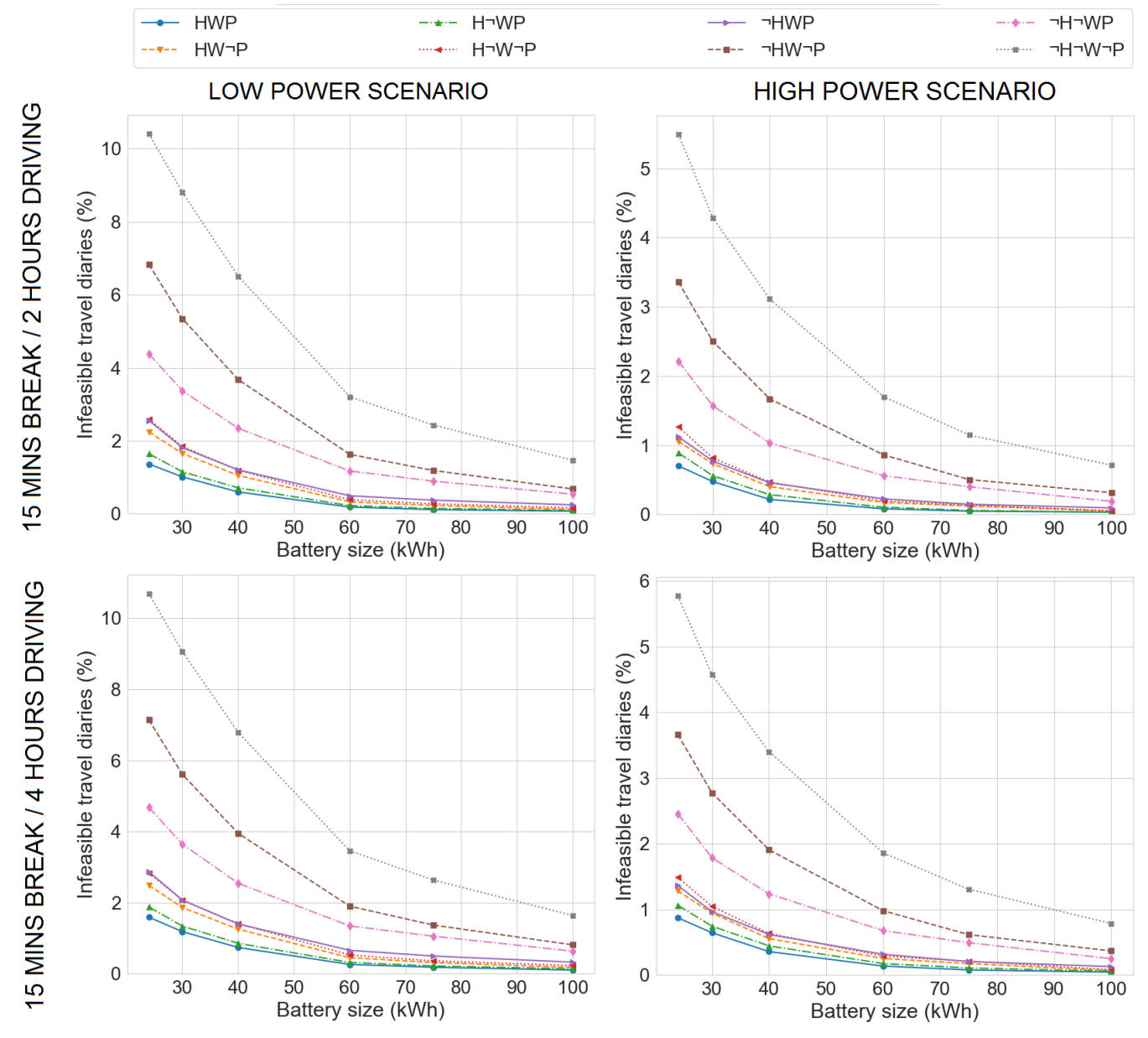

Figure 16: Proportion of NTS travel diaries made infeasible by EV charging for varying battery sizes and levels of charging access with comparison to ICEV analysis for low power (left) and high power (right) charging scenarios for both the Highway Code Rule 91 case (top) and the sensitivity case (bottom)

Figure 16 shows another metric - besides the total time penalty of the inconvenience of EV charging. For individuals who lack access to parked charging, a significant proportion (up to $10.7 \%$, in the case of 24 $\mathrm{kWh}$ EVs under the low power charging scenario in the sensitivity case where drivers take a 15 minute break every 4 hours) of travel diaries are rendered infeasible by the use of an EV. Increasing access to charging is shown to dramatically reduce the proportion of travel diaries rendered unfeasible, with access to home charging or access to work and public charging reducing the 
proportion of infeasible travel diaries by up to a factor of 4 . It is shown that increasing the charger power available also offers a significant improvement; the $10.7 \%$ of travel diaries for the above circumstances is reduced to $5.8 \%$ for the high power charging scenario. Increasing the battery capacity reduces the proportion of infeasible travel diaries, though for battery capacities of 60 $\mathrm{kWh}$ and over this rate of reduction decreases. It is suggested that this is due to a small proportion of travel diaries with longer journeys sufficiently close together such that an EV with any combination of the parameters trialled is unable to make the start time of the second journey from a delayed finish time of the first.

As shown in Figure 16, the assumption regarding how often breaks are taken during long journeys has a subtle effect on how many travel diaries are deemed infeasible. This could be due to the small presence of long trips in the data (Figure 13), or that the parking events tend to be of greater duration (and therefore more likely to be able to absorb any delay from having to stop and charge) for long journeys than shorter ones: the average parking duration following a journey of 2 hours or longer is 16.2 hours, compared to 10.6 hours for those following journeys under 2 hours (based on all journeys in the NTS dataset).

\section{Discussion}

Across all the results presented in section 3, it is clear that achieving convenience parity between EV charging and ICEV fuelling can be done by a combination of increasing battery size, increasing charging power and most importantly - enabling access to charging at more locations.

It seems that the directions pursued by EV manufacturers (who will influence battery size and what level of power the vehicles can charge at) and business owners, employers and local authorities (who will influence the provision of publicly available charging locations) are moving toward a trend of increased EV charging convenience.

Battery sizes that have historically been constrained to the higher end of the market are becoming more widespread. For example, the Tesla Model S - a well-established long-range EV with battery configurations between 60 and $100 \mathrm{kWh}$ - starts at $£ 75,500$ in the UK including government subsidies [45], remaining outside of the budgets of most would-be EV consumers. In 2019, Tesla are launching their own Model 3 in the UK with battery capacities between 50 and $75 \mathrm{kWh}$ at the more modestly priced $£ 38,800$ after 
government subsidies [46] and Hyundai are pricing their Kona Electric with a $64 \mathrm{kWh}$ battery at $£ 32,845$ after government subsidies [47]. Furthermore, 'affordable' EVs are increasing in battery size as new versions are released: as shown in Figure 3, three versions of the Nissan Leaf [4] have spanned three battery capacities in as many years from $24 \mathrm{kWh}$ to $40 \mathrm{kWh}$.

Charging power is also increasing. $150 \mathrm{~kW}$ rapid charging is becoming the new norm for rapid charging, with BP Chargemaster - the UK's largest public EV charging network operator — planning to open $400150 \mathrm{~kW}$ chargers by 2021 with the first being installed in 2019 [48]. The first $350 \mathrm{~kW}$ charger has been installed in the UK as of April 2019 [49], with cross-European joint venture Ionity planning to build $50350 \mathrm{~kW}$ chargers in the UK by 2020 [50]. New EV models are moving towards being able to accept these levels of power: the Audi E-Tron can accept $150 \mathrm{~kW}$ [51] and the Porsche Taycan to be released in 2019 - is confirmed to have a $350 \mathrm{~kW}$ charging capability [52].

It also seems likely that future EV users will have access to charging at more locations. As shown in Figures 9-12, having access to home charging renders convenience parity achievable at modest battery sizes and charging levels. For the estimated $43 \%$ of households that lack access to off-street parking in the UK [53], new options are emerging such as the Connected Kerb system, designed to allow low-impact charging infrastructure to be installed in the kerbs of residential streets [54] and the Char.gy network of lamppost charging [55], designed for those who park their vehicles on-street while at home. Increasingly, private companies are looking to provide free EV charging to attract more custom: as aforementioned, three of the UK's biggest supermarket chains have announced plans to install free-to-use EV charging infrastructure at their stores [27-29].

\section{Conclusions and Further Work}

This paper has presented analysis of 39,020 travel diaries from the UK National Travel Survey to investigate the inconvenience of EV charging relative to ICEV fuelling. Inconvenience was quantified in terms of the time penalty suffered from charging or fuelling actions to service journeys taken over the course of a week.

The key contribution from this paper is the quantitative analysis of the proportion of week-long travel diaries for which a driver could switch an ICEV for an $\mathrm{EV}$ with no relative inconvenience related to maintaining a level of 
energy storage in their vehicles required to make the trips that they desire. It was found that the majority of $\mathrm{EV}$ drivers who have access to charging at home can expect convenience parity compared to ICEV drivers, even for modest battery sizes. Increasing the battery capacity and charger power enables those without access to charging at home to experience a much lesser time penalty associated with charging than they would before, but there remains a big divide in the convenience of personal mobility between those who can charge at home and those who cannot. It is therefore established that a critical part of a future transportation system that supports EVs is an abundance of facilities with which people can charge as they park at home, regardless of whether that may be in a private driveway or not.

Aside from day-to-day driving as presented in the travel diary analysis, particular attention was given to journeys whose distance is greater than the range of the vehicle and hence cannot be made on a single charge. For this analysis, the assumption that drivers are compliant to the Highway Code had a significant effect. If they are compliant, it was found that, in the low power charging scenario for battery capacities of $40 \mathrm{kWh}$ and above, the majority of trips which were of greater distance than the range of the vehicle would involve no delay resulting from charging that could not be fitted into breaks that should be taken anyway. This was true for all battery capacities modelled for the high power charging scenario. To the extent that the assumption of there being sufficient charging infrastructure such that a vehicle can immediately locate a charger upon reaching a minimum range of $25 \mathrm{~km}$ is valid, for battery capacities of $60 \mathrm{kWh}$ and above, the proportion of journeys that are expected to face an additional delay from charging - $0.007 \%$ and $0.0002 \%$ for the low and high power charging scenarios respectively — are negligible. For the sensitivity case where drivers are not compliant with the Highway Code, a battery capacity of $60 \mathrm{kWh}$ means that an expected $0.21 \%$ and $0.12 \%$ of trips are expected to involve a delay from charging from the low and high power charging scenarios respectively.

It has been discussed how the developing trends in the EV industry regarding battery size, charger power and charging infrastructure are likely to enable convenience parity for a wider section of EV users, and as such these trends are promising for the mass uptake of EVs that is widely cited as being required in order to reach net-zero greenhouse gas emissions. Although the trends observed in the EV market may be moving in the right direction, there are still multiple challenges: EVs remain of high up-front cost and the development of extensive charging infrastructure - which on the basis of the 
results from this paper could be argued as the most important technological development required for the mass uptake of EVs - requires significant capital expenditure, both in terms of the charging hardware itself and any grid reinforcements that must be made in order to accommodate the charging demand. Thus, continued support of the sector is critical.

Based on the contributions made by this paper, the following pieces of further work are identified:

1. To disaggregate the travel data into sets that represent different driving behaviours, e.g. travel diaries that contain regular long journeys and those that are clearly that of a commuter. Results could then be published on the expected charging time penalty for different groups of drivers.

2. To expand upon the model of vehicle energy consumption by considering how the need to charge (and hence inconvenience associated with doing so) is affected by driving style and the additional power demand caused by air conditioning and heating.

3. To investigate alternative models of representing human behaviour and the impact of 'non-ideal' decision-making on the resulting inconvenience of charging.

4. To carry out analysis with the consideration of non-binary levels of access to charging. For example, while a driver might have access to charging at some public destinations (Table 2), they may not have access to charging at all public destinations they visit. Furthermore, if on-street home charging becomes widely available, then any one charger may be expected to be available less than a private off-street home charger and the time penalty associated with finding a parking space with an available on-street charger would likely be greater. This rate of successful access to charging will have an impact on the results presented in this paper, and the value of a sensitivity study into the extent of that impact is highlighted.

5. To investigate the relative cost and benefits of increasing battery size, increasing charger power and widening access to EV charging as methods of making EV charging more convenient.

6. To investigate how much EV charging will likely need to be done at various locations (within the workplace or public destination categories) based on the frequency at which vehicles visit these destinations. From this point, infrastructure planning could be informed as to the optimal 
number of charge points to install at each location and electricity network planning could be informed as to the likely demand profiles that would be seen at that point in the network.

7. To investigate the effect of continuing battery degradation on the results presented, given that the capacity of the battery will fade as they are charged and discharged, thus reducing the range of the vehicle and the charging rate attainable, thereby increasing the required frequency of charging stops and reducing the amount of energy that can be drawn from a given duration of charging.

\section{Acknowledgements}

This work has been done through the Engineering and Physical Sciences Research Council (EPSRC) Centre for Doctoral Training on Future Power Networks and Smart Grids at the University of Strathclyde, funded by grant EP/L015471/1. Grateful thanks are expressed to Dr Waqquas Bukhsh for his help on mathematical formulations within this paper.

\section{Data Availability}

Data used to perform the analyses presented in this paper are all found online. The UK National Travel Survey data is available through the UK Data Service [33] to registered users. The US Environmental Protection Agency fuel consumption data is available to download via their website [3].

\section{References}

[1] Committee on Climate Change, "Net Zero: The UK's contribution to stopping global warming," Tech. Rep. May, 2019.

[2] US Department of Energy, "Fuel Properties Comparison," 2019. [Online]. Available: https://goo.gl/eU1bvK

[3] United States Environmental Protection Agency, "Data on Cars used for Testing Fuel Economy," 2019. [Online]. Available: https://goo.gl/jwrFQm

[4] Nissan, "Leaf," 2017. [Online]. Available: https://goo.gl/W1byqZ 
[5] US Department of Energy, "All-Electric Vehicles." [Online]. Available: https://bit.ly/2ed7xfu

[6] "ABB powers e-mobility with launch of first 150-350 kW high power car charger," 2019. [Online]. Available: https://goo.gl/z4sf98

[7] National Grid, "Forecourt Thoughts: Mass fast charging of electric vehicles," 2017. [Online]. Available: https://goo.gl/8v2T2X

[8] T. Gnann, S. Funke, N. Jakobsson, P. Plötz, F. Sprei, and A. Bennehag, "Fast charging infrastructure for electric vehicles: Today's situation and future needs," Transportation Research Part D: Transport and Environment, vol. 62, pp. 314-329, 2018. [Online]. Available: https://doi.org/10.1016/j.trd.2018.03.004

[9] Porsche Engineering, "New Possibilities with 800-Volt Charging," 2016. [Online]. Available: https://goo.gl/TE9ohV

[10] L. Donaldson, "Making fast-charging electric vehicles a possibility," Materials Today, vol. 21, no. 2, pp. 105-106, 2018. [Online]. Available: http://dx.doi.org/10.1016/j.mattod.2018.01.028

[11] N. S. Pearre, W. Kempton, R. L. Guensler, and V. V. Elango, "Electric vehicles: How much range is required for a day's driving?" Transportation Research Part C: Emerging Technologies, vol. 19, no. 6, pp. 1171-1184, 2011. [Online]. Available: http://dx.doi.org/10.1016/j.trc.2010.12.010

[12] J. Axsen, K. S. Kurani, and A. Burke, "Are batteries ready for plug-in hybrid buyers?" Transport Policy, vol. 17, no. 3, pp. 173-182, 2010. [Online]. Available: http://dx.doi.org/10.1016/j.tranpol.2010.01.004

[13] Z. Rezvani, J. Jansson, and J. Bodin, "Advances in consumer electric vehicle adoption research: A review and research agenda," Transportation Research Part D: Transport and Environment, vol. 34, pp. 122-136. [Online]. Available: http://dx.doi.org/10.1016/j.trd.2014.10.010

[14] D. Diamond, "The impact of government incentives for hybridelectric vehicles: Evidence from US states," Energy Policy, vol. 37, no. 3, pp. 972-983. [Online]. Available: http://dx.doi.org/10.1016/j.enpol.2008.09.094 
[15] O. Egbue and S. Long, "Barriers to widespread adoption of electric vehicles: An analysis of consumer attitudes and perceptions," Energy Policy, vol. 48, no. 2012, pp. 717-729, 2012. [Online]. Available: http://dx.doi.org/10.1016/j.enpol.2012.06.009

[16] A. Dimitropoulos, P. Rietveld, and J. N. van Ommeren, "Consumer valuation of changes in driving range: A meta-analysis," Transportation Research Part A: Policy and Practice, vol. 55, pp. 27-45, 2013. [Online]. Available: http://dx.doi.org/10.1016/j.tra.2013.08.001

[17] M. Giansoldati, R. Danielis, L. Rotaris, and M. Scorrano, "The role of driving range in consumers' purchasing decision for electric cars in Italy," Energy Policy, vol. 165, pp. 267-274. [Online]. Available: https://doi.org/10.1016/j.energy.2018.09.095

[18] T. Franke and J. F. Krems, "What drives range preferences in electric vehicle users?" Transport Policy, vol. 30, pp. 56-62, 2013. [Online]. Available: http://dx.doi.org/10.1016/j.tranpol.2013.07.005

[19] "Highway Code Rule 91," 2019. [Online]. Available: https://goo.gl/MtyWLS

[20] C. C. Rolim, G. N. Gonçalves, T. L. Farias, and Ó. Rodrigues, "Impacts of electric vehicle adoption on driver behavior and environmental performance," vol. 54, pp. 706-715. [Online]. Available: http://dx.doi.org/10.1016/j.sbspro.2012.09.788

[21] M. Helmbrecht, C. Olaverri-Monreal, K. Bengler, R. Vilimek, and A. Keinath, "How electric vehicles affect driving behavioral patterns," IEEE Intelligent Transportation Systems Magazine, vol. 6, no. 3, pp. 2232. [Online]. Available: http://dx.doi.org/10.1109/MITS.2014.2315758

[22] Zap-Map, "Journey Planner." [Online]. Available: https://www.zapmap.com/route-planner/

[23] Zap-Map, "Charging Point Statistics 2019," 2018. [Online]. Available: https://goo.gl/xZ45CH

[24] UK Petroleum Industry Association (UKPIA), "Statistical Review 2018," Tech. Rep., 2018. [Online]. Available: https://bit.ly/2koVXS7 
[25] D. P. Tuttle and K. M. Kockelman, "Electrified Vehicle Technology Trends, Infrastructure Implications, And Cost Comparisons," Journal of the Transportation Research Forum, vol. 51, no. 1, pp. 35-51. [Online]. Available: http://dx.doi.org/10.5399/osu/jtrf.51.1.2806

[26] Z. Lin and D. L. Greene, "Promoting the market for plug-in hybrid and battery electric vehicles," Transportation Research Record, no. 2252, pp. 49-56. [Online]. Available: http://dx.doi.org/10.3141/2252-07

[27] Pod-Point, "Lidl Rapid Charging Stations," 2019. [Online]. Available: http://bit.ly/2YXdOh8

[28] BBC News, "Tesco and VW plan free electric car charging points," 2018. [Online]. Available: https://bbc.in/2QguHks

[29] Zap-Map, "Morrisons to install GeniePoint rapid chargers," 2019. [Online]. Available: http://bit.ly/2KAA9vP

[30] —-, "Public Charging Networks," 2019. [Online]. Available: https://goo.gl/sX6mYr

[31] J. D. Bishop, C. J. Axon, D. Bonilla, M. Tran, D. Banister, and M. D. McCulloch, "Evaluating the impact of V2G services on the degradation of batteries in PHEV and EV," $A p$ plied Energy, vol. 111, pp. 206-218, 2013. [Online]. Available: http://dx.doi.org/10.1016/j.apenergy.2013.04.094

[32] X. Tang, C. Zou, K. Yao, J. Lu, Y. Xia, and F. Gao, "Aging trajectory prediction for lithium-ion batteries via model migration and Bayesian Monte Carlo method," Applied Energy, vol. 254, no. May, 2019. [Online]. Available: https://doi.org/10.1016/j.apenergy.2019.113591

[33] UK Data Service, "UK National Travel Survey 2002-2016," 2019. [Online]. Available: https://goo.gl/LgtfDd

[34] Department for Transport, "Free Flow Vehicle Speed Statistics: Great Britain 2015," Tech. Rep., 2015.

[35] M. Tabari and A. Yazdani, "An Energy Management Strategy for a DC Distribution System for Power System Integration of Plug-In Electric Vehicles," IEEE Transactions on Smart Grid, no. 2, pp. 659-668. [Online]. Available: https://doi.org/10.1109/TSG.2015.2424323 
[36] F. Marra, G. Y. Yang, C. Træ holt, E. Larsen, C. N. Rasmussen, and S. You, "Demand profile study of battery electric vehicle under different charging options," IEEE Power and Energy Society General Meeting. [Online]. Available: http://dx.doi.org/10.1109/PESGM.2012.6345063

[37] M. Gjelaj, S. Hashemi, P. B. Andersen, and C. Træholt, "Grid Services Provision from Batteries within Charging Stations by using a Stochastic Planning Method of the EVs Demand Grid Services Provision from Batteries within Charging Stations by using a Stochastic Planning Method of the EVs Demand." [Online]. Available: http://bit.ly/2ZHlyVV

[38] P. Zhang, K. Qian, C. Zhou, B. G. Stewart, and D. M. Hepburn, "A methodology for optimization of power systems demand due to electric vehicle charging load," IEEE Transactions on Power Systems, vol. 27, no. 3, pp. 1628-1636. [Online]. Available: http://dx.doi.org/10.1109/TPWRS.2012.2186595

[39] S. I. Vagropoulos and A. G. Bakirtzis, "Optimal bidding strategy for electric vehicle aggregators in electricity markets," IEEE Transactions on Power Systems, vol. 28, no. 4, pp. 4031-4041, 2013. [Online]. Available: http://dx.doi.org/10.1109/TPWRS.2013.2274673

[40] W. Kempton, V. Udo, K. Huber, K. Komara, S. Letendre, S. Baker, D. Brunner, and N. Pearre, "A Test of Vehicle-to-Grid (V2G) for Energy Storage and Frequency Regulation in the PJM System: Results from an Industry-University Research Partnership," Tech. Rep. [Online]. Available: http://bit.ly/2kSTcsz

[41] L. R. Chen, S. L. Wu, D. T. Shieh, and T. R. Chen, "Sinusoidal-ripple-current charging strategy and optimal charging frequency study for Li-ion batteries," IEEE Transactions on Industrial Electronics, vol. 60, no. 1, pp. 88-97. [Online]. Available: http://dx.doi.org/10.1109/TIE.2012.2186106

[42] J. W. Huang, Y. H. Liu, S. C. Wang, and Z. Z. Yang, "Fuzzy-control-based five-step Li-ion battery charger," Proceedings of the International Conference on Power Electronics and Drive Systems, pp. 1547-1551, 2009. [Online]. Available: http://dx.doi.org/10.1109/PEDS.2009.5385780 
[43] T. T. Vo, X. Chen, W. Shen, and A. Kapoor, "New charging strategy for lithium-ion batteries based on the integration of Taguchi method and state of charge estimation," Journal of Power Sources, vol. 273, pp. 413-422, 2015. [Online]. Available: http://dx.doi.org/10.1016/j.jpowsour.2014.09.108

[44] Y. Li, K. Li, Y. Xie, J. Liu, C. Fu, and B. Liu, "Optimized charging of lithium-ion battery for electric vehicles: adaptive multistage constant current-constant voltage charging strategy," Renewable Energy, vol. 146, pp. 2688-2699, 2019. [Online]. Available: http://dx.doi.org/10.1016/j.renene.2019.08.077

[45] Tesla, "Model S," 2019. [Online]. Available: https://goo.gl/zKF5c7

[46] Tesla, "Model 3," 2019. [Online]. Available: http://bit.ly/2WhRK3y

[47] Hyundai, "Kona Electric," 2019. [Online]. Available: http://bit.ly/2K2dDO3

[48] BP Chargemaster, "BP confirms rollout of $150 \mathrm{~kW}$ chargers on $\mathrm{BP}$ Forecourts," 2019. [Online]. Available: http://bit.ly/2En53Wp

[49] Fastned, "Press release: Fastned opens its first 350kW-ready fast charging station in the United Kingdom," 2019. [Online]. Available: http://bit.ly/30yohlk

[50] Ionity, "Our Network," 2019. [Online]. Available: https://ionity.eu/

[51] Audi, "E-Tron - Charging," 2019. [Online]. Available: http://bit.ly/2VT0g9I

[52] Porsche, "Mission E," 2018. [Online]. Available: http://bit.ly/2w9gpJ7

[53] Department for Transport, "Public experiences of and attitudes towards parking," 2008. [Online]. Available: https://goo.gl/PQo7qX

[54] Connected Kerb, "Low Impact EV Charging," 2019. [Online]. Available: http://bit.ly/2w9iaG5

[55] Char.gy, "Lamppost electric vehicle charging for everyone," 2019. [Online]. Available: https://char.gy/ 